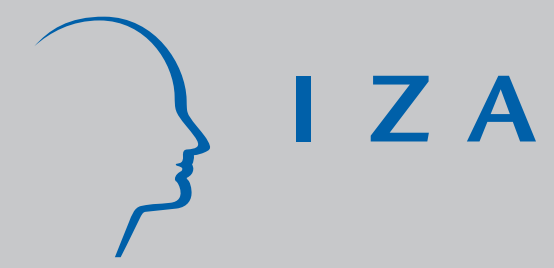

IZA DP No. 232

The Effect of Non-Standard Employment on Mental Health in Britain

Elena Bardasi

Marco Francesconi

December 2000 


\title{
The Effect of Non-Standard Employment on Mental Health in Britain
}

\author{
Elena Bardasi \\ Institute of Social and Economic Research, \\ University of Essex \\ Marco Francesconi \\ Institute of Social and Economic Research, \\ University of Essex and IZA, Bonn \\ Discussion Paper No. 232 \\ December 2000 \\ IZA \\ P.O. Box 7240 \\ D-53072 Bonn \\ Germany \\ Tel.: +49-228-3894-0 \\ Fax: +49-228-3894-210 \\ Email: iza@iza.org
}

This Discussion Paper is issued within the framework of IZA's research area The Future of Work. Any opinions expressed here are those of the author(s) and not those of the institute. Research disseminated by IZA may include views on policy, but the institute itself takes no institutional policy positions.

The Institute for the Study of Labor (IZA) in Bonn is a local and virtual international research center and a place of communication between science, politics and business. IZA is an independent, nonprofit limited liability company (Gesellschaft mit beschränkter Haftung) supported by the Deutsche Post AG. The center is associated with the University of Bonn and offers a stimulating research environment through its research networks, research support, and visitors and doctoral programs. IZA engages in (i) original and internationally competitive research in all fields of labor economics, (ii) development of policy concepts, and (iii) dissemination of research results and concepts to the interested public. The current research program deals with (1) mobility and flexibility of labor markets, (2) internationalization of labor markets and European integration, (3) the welfare state and labor markets, (4) labor markets in transition, (5) the future of work, (6) project evaluation and (7) general labor economics.

IZA Discussion Papers often represent preliminary work and are circulated to encourage discussion. Citation of such a paper should account for its provisional character. 
IZA Discussion Paper No. 232

December 2000

\section{ABSTRACT \\ The Effect of Non-Standard Employment on Mental Health in Britain*}

This paper explores the relationship between non-standard types of employment and mental health. The analysis uses data on workers from the first seven waves of the British Household Panel Study, 1991-97. Four different types of non-standard employment (non-standard contracts, places, times, and weekly hours of work) are analysed and the General Health Questionnaire (GHQ) index is used as the measure of mental health. We find evidence of only a modest effect of all types of flexible employment on the GHQ scores of men and women. Although the workers' non-standard employment behaviour does not significantly vary with their endowments and unobserved inputs, population health heterogeneity may still have a critical effect on the observed changes in labour market behaviour. Finally, we find some significant effect of non-standard employment on mental health when the sample is stratified by age and education.

JEL Classification: I12, J21, J22

Keywords: $\quad$ Mental health, non-standard employment, panel data, fixed-effects model, endowment heterogeneity

Marco Francesconi

ISER

University of Essex

Colchester CO4 3SQ

UK

Tel.: +44 (0) 1206873534

Fax: +44 (0) 1206873151

Email:mfranc@essex.ac.uk

\footnotetext{
* We thank Alison Booth, Willy Brown, Stephen Jenkins, David Pevalin and seminar participants at the Universities of Bilbao and Essex and the 2000 Conference of the British Association for the Advancement of Science (Imperial College, London) for helpful comments. We are grateful to the ESRC for financial support. Marco Francesconi gratefully acknowledges the financial support under "The Future of Work: Flexible Employment, Part-time Work and Career Development in Britain" Award No. L212 252007.
} 


\section{NON-TECHNICAL SUMMARY}

This paper analyses the relationship between non-standard types of employment - defined in terms of contracts, places, times and hours of work - and mental health in Britain. Labour market flexibility has been generally welcomed by employers and policy makers as a means of improving workers' performance and adaptability in the face of technical change and increasing globalisation. Although several studies document the growth and diffusion of non-standard jobs in Britain, no research has been conducted to investigate whether experience of work in such jobs has a positive or negative impact on individuals' mental health. Yet knowing how mental health depends on non-standard employment is clearly of policy relevance because it provides key equity considerations to complement the efficiency arguments advocated by employers. Furthermore, a proper understanding of this relationship is necessary to inform public debates over questions such as the appropriateness of psychological disability-related transfers, or the desirability of mandating minimum insurance coverage for psychiatric services. Certain private sector decisions, e.g., the funding of employee assistance programs, also depends on the degree to which psychological distress impairs workplace performance, relative to the cost of implementing such programs.

The fact that people choose whether to be employed in non-standard employment means that employment status is potentially endogenous to mental health. Moreover, if unobserved inputs, which people select to affect their health status (such as eating habits or physical exercise), and fixed health endowments determine the choice of non-standard employment, then conventional econometric procedures cannot be applied. Not only are least squares estimates inadequate to identify the effect of flexible working arrangements on mental health, but also fixed-effects estimates fail, as long as there are self-selected unobserved health inputs that affect labour market behaviour and health status and vary across individuals and over time. Two-period lagged first differences, however, yield consistent estimates of the effect of non-standard employment on psychological fitness under some strong orthogonality conditions on the process governing the dynamic path of the unobservable inputs.

Our empirical analysis is performed using longitudinal data on male and female workers drawn from the first seven waves of the British Household Panel Survey, 19911997. The focus of our estimation is on one important mental health indicator, which is derived from the General Health Questionnaire (GHQ) and is considered to be a reliable measure of minor psychiatric morbidity. We use information on a set of behavioural variables that are likely to affect mental health, including education, number of children, number of cigarettes smoked, and several types of non-standard employment (e.g., being on a fixed-term contract, working long hours, and being on rotating shifts).

There is evidence of only a limited effect of all types of flexible employment on male and female workers' GHQ scores. We also find that the non-standard employment behaviour among British workers does not significantly vary with their health endowments 
and their hard-to-measure inputs. This does not necessarily imply that endowments and unobserved inputs are inconsequential to workers' labour market decisions, because they may have offsetting impacts. The effect of non-standard employment on mental health is identified through workers that move in and out of non-standard types of employment. As movers may be characterised by heterogeneous preferences and constraints, we partition the sample by age at the start of the panel and by education to attenuate the extent of this heterogeneity. The effects for workers aged less than 30 are strongest in the case of nonstandard contracts and non-standard hours for men, and all types of non-standard employment for women (with the exception of hours). While the mental health status of men and women aged 45 or more is especially responsive to non-standard times and nonstandard hours of work, respectively. Highly educated women and men from all the education groups tend to experience some significant health changes due to contract and place-of-work flexibility. In addition, women's mental fitness is sensitive to flexible time and flexible hours arrangements regardless of their position in the education distribution. 


\section{Introduction}

This paper analyses the relationship between non-standard types of employment and mental health in Britain. ${ }^{1}$ Labour market flexibility has been generally welcomed by employers and policy makers as a means of improving workers' performance and adaptability in the face of technical change and increasing globalisation. Although several studies document the growth and diffusion of non-standard jobs in Britain (Dex and McCulloch 1995; Francesconi 2000), no research has been conducted to investigate whether experience of work in such jobs has a positive or negative impact on individuals' mental health. Yet knowing how mental health depends on non-standard employment is clearly of policy relevance because it provides key equity considerations to complement the efficiency arguments advocated by employers. Furthermore, a proper understanding of this relationship is necessary to inform public policy debates over questions such as the appropriateness of psychological disability-related transfers, or the desirability of mandating minimum insurance coverage for psychiatric services. Certain private sector decisions, e.g., the funding of employee assistance programs, also depend on the degree to which psychological distress impairs workplace performance, relative to the cost of implementing such programs.

How is non-standard employment expected to affect mental health? Unfortunately, there is no theory that explicitly models this labour market state and its relationship to mental health, nor is there any wisdom based on previous empirical analyses. A few studies claim that long or inflexible hours of work have a negative impact on the life of American

\footnotetext{
${ }^{1}$ We define 'standard' workers as those employed on a permanent contract, working at the employer's premises, during the day and for between 30 and 48 hours per week. Non-standard workers are those who do not fit this definition - that is, they are employed on temporary contracts, or work away from the employer's premises, or for shorter or longer hours than the generally accepted norm, or not during the regular working day. Details are given in the section describing the data (Section 3 below).
} 
families. Marital discord and dissolution, child neglect and sleep deprivation have been blamed on unusual work schedules and, particularly, on long work hours (Schor 1992; Presser 2000). There is also evidence that family-friendly policies are not effective in relieving pressure on households, and that employers encourage employees to choose work over family (Hochschild 1997). To the extent that a balanced family life and good mental health are positively correlated, we would expect mental health to be adversely affected by the experience of some types of non-standard employment. There are studies, however, that find small and often insignificant effects of hours of work on the probability of divorce (Johnson 1999), and others recognise that more diverse and flexible work schedules may indeed help families (and their members), especially in relation to childcare arrangements (Presser 1995). Moreover, some people may well choose these jobs not only because they provide a valuable source of income but also because they are an efficient means of coping with binding time or place constraints (e.g., working in the morning only or working at home). In this case, we would expect these non-standard forms of employment to improve individuals' mental health. Without a theory providing clear-cut predictions and with only indirect results providing partially conflicting evidence for different types of flexible jobs, this paper estimates an econometric model which identifies the effect of non-standard employment on workers' mental health.

The fact that people choose their job type (i.e., whether or not to be employed in a non-standard job) raises the important issue of 'endogeneity' of non-standard employment to the determination of individual's health. Many econometric studies have investigated this issue in analysing the relationship between health and unemployment (Hamilton et al. 
1997; Kerkhofs and Lindeboom 1997; Theodossiou 1998; Wadsworth et al. 1999). ${ }^{2}$ The procedures used to identify the effect of unemployment on health vary quite substantially, with some studies using simultaneous equation models and others using two-stage techniques or proxy and matching methods. The procedure used in this paper is different and is motivated by our conceptual framework. This is based on an individual's mental health production function, and accounts for the endogeneity of unobservable, self-selected health inputs that are likely to be correlated with exogenous endowments. While the concept of a health production function, originally developed by Grossman (1972), is implicit in most of the recent studies that analyse the relationship between unemployment and mental health, it has not been fully exploited. This concept is powerful because it distinguishes between health production technology and preference orderings, offers a suitable framework to interpret the estimated parameters structurally, and disciplines the econometric analysis by guiding the selection of economically meaningful explanatory variables.

Our empirical analysis uses longitudinal data on male and female workers drawn from the first seven waves of the British Household Panel Survey, 1991-1997. Our focus is on one important mental health indicator, derived from the General Health Questionnaire (GHQ) and considered to be a reliable measure of minor psychiatric morbidity. We use information on a set of behavioural variables that are likely to affect mental health, including work experience, education, number of cigarettes smoked, and several types of

\footnotetext{
${ }^{2}$ For a comprehensive survey of this literature, see Jin et al. (1995) and Murphy and Athansou (1999). Another well-established literature is concerned with the opposite casual relationship, i.e., the impact of mental health on employment, productivity and earnings (Bartel and Taubman 1986; Ettner et al. 1997), as well as the impact of mental health on criminal activity (Link et al. 1992) and divorce (Bartel and Taubman 1986). For an up-to-date review, see Frank and McGuire (2000). Most of these studies use a different measure of mental health from that used in this paper. Their mental health measure refers to severe psychiatric disorders, e.g., schizophrenia, major depression, mania, dysthymia, and substance abuse. Our measure, described in detail below, identifies current symptoms of distress and demoralisation and is designed to identify individuals at high risk of emotional distress.
} 
non-standard employment (e.g., being on a fixed-term contract, working long hours, and being on rotating shifts). In Section 2 we outline our conceptual framework to interpret the estimation of the health production function and to assess the effect of health heterogeneity and unmeasured endogenous inputs on the observed health outcome. We present the data in

Section 3, which contains a detailed description of the GHQ index and the types of nonstandard employment. Section 4 reports the production function estimates and discusses the effect of workers' health endowment on workers' non-standard employment behaviour. Our estimates indicate there is only a modest effect of all types of flexible employment on the GHQ index of men and women. In addition, the patterns of non-standard employment do not significantly vary with workers' health endowments and unobserved inputs. This does not necessarily imply that endowments and unobserved inputs are inconsequential to workers' labour market decisions, because they may have offsetting effects. In Section 5, we analyse whether or not the effects of non-standard employment on mental health differ by age and education groups. We find evidence of some significant age and education differences in the relationship between non-standard employment and mental health. Section 6 summarises our principal conclusions.

\section{Analytical framework}

Our empirical analysis is based on the conceptual framework of a health production function (Grossman 1972; Rosenzweig and Schultz 1983; Grossman and Joyce 1990). It is clear that unobserved factors, such as an individual's exogenous health endowment, and unobserved endogenous inputs, such as exercise, avoidance of stress and eating habits, can substantially affect the determination of mental health outcomes. If an individual's behaviour is shaped, at least in part, by knowledge of the health endowment or if the 
unobserved endogenous inputs are correlated with the included inputs, then the level (or cross-sectional) estimates of the mental health technology when measured by direct correlations will be biased. Furthermore, the optimal allocation of resources in the production of mental health will change with variations in exogenous factors (e.g., local labour market conditions and the availability of specialists) as well as with variations in observed endogenous inputs. Thus in terms of the level of mental health, the whole past history, including the time paths of inputs and labour market decisions, will be relevant. Accurate identification of the entire time profile of all inputs and decisions for each individual is crucial. This requires data that are seldom available.

The analysis of mental health changes over a restricted period of time has already been used to circumvent (or, at least, attenuate) some of the most serious econometric difficulties (Bishai 1996; Kerkhofs and Lindeboom 1997). ${ }^{3}$ Although a change (or valueadded) model reduces the range of possible alternative interpretations, it does not provide estimates that can be unambiguously interpreted and does not eliminate the necessity of imposing important auxiliary assumptions. We illustrate this point with the following econometric framework. We start by showing the inadequacy of the level model, which estimates the relationship between health and employment status cross-sectionally. Let $H_{i t}$ denote the mental health of the $i$-th individual at time $t$. This can be thought of as a linearly additive function of individual-specific inputs, $X_{i t}$, employment-specific inputs, $C_{i t}$, exogenous environmental variables, $Z_{i t}$, and unobservables, $u_{i t}$. The level of mental health at any point can be simply written as ${ }^{4}$

$$
H_{i t}=\alpha X_{i t}+\beta C_{i t}+\gamma Z_{i t}+u_{i t} .
$$

\footnotetext{
${ }^{3}$ Hanushek (1992) originally introduced this approach, also known as 'value-added' approach, in analysing school achievement growth models.
} 
Elements of the $X$ vector are education, marital status, number of children, occupation, and number of cigarettes smoked in a week. An example of elements of the $Z$ vector is local labour market conditions. This paper is particularly concerned with the impact of employment-specific inputs, $C$, examples of which are being employed on a fixed-term contract, working at home, working long hours or working in rotating shifts. A full description of the variables used in the empirical analysis is given in Section 3.

Least squares (level) estimates of $\beta$ in (1) will be biased as long as the covariance between $u_{i t}$ and $C_{i t}$ is non-zero. This is case if, for example,

$$
u_{i t}=a_{1} e_{i}+a_{2} q_{i t}+\varepsilon_{i t}
$$

and the stochastic process that determines the employment-specific inputs is given by

$$
C_{i t}=b_{0} \eta_{i}+b_{1} e_{i}+b_{2} q_{i t}+v_{i t} \text {, }
$$

where $e_{i}$ denotes the individual-specific health endowment, $\eta_{i}$ is the other-than-health endowment (e.g., earnings endowment), $q_{i t}$ denotes unmeasured or unmeasurable endogenous inputs which reflect such healthy behaviours as proper eating habits, appropriate physical exercise and avoidance of stress, and which are allowed to vary over time (perhaps in response to changes in $C_{i t}$ ), and $\varepsilon_{i t}$ and $v_{i t}$ are idiosyncratic disturbances with zero mean. ${ }^{5}$ We assume that $\mathrm{E}\left(v_{i t} v_{i t-k}\right)=\mathrm{E}\left(\varepsilon_{i t} \varepsilon_{i t-k}\right)=\mathrm{E}\left(v_{i t} \eta_{i}\right)=\mathrm{E}\left(v_{i t} e_{i}\right)=\mathrm{E}\left(v_{i t} q_{i t}\right)=\mathrm{E}\left(v_{i t} \varepsilon_{i t}\right)=$ $\mathrm{E}\left(\varepsilon_{i t} \eta_{i}\right)=\mathrm{E}\left(\varepsilon_{i t} e_{i}\right)=\mathrm{E}\left(\varepsilon_{i t} q_{i t}\right)=\mathrm{E}\left(e_{i}\right)=\mathrm{E}\left(q_{i t}\right)=\mathrm{E}\left(\eta_{i}\right)=0$, for all time periods $t$ and $k$, and all individuals $i$. From (1)-(3) it can be seen that

$$
\operatorname{cov}\left(C_{i t}, u_{i t}\right)=a_{1} b_{0} \sigma_{e \eta}+a_{2} b_{0} \sigma_{q \eta}+\left(a_{2} b_{1}+a_{1} b_{2}\right) \sigma_{q e}+a_{1} b_{1} \sigma_{e}^{2}+a_{2} b_{2} \sigma_{q}^{2}
$$

\footnotetext{
${ }^{4}$ An additive and linear production function is also employed in Grossman and Joyce's (1990) study of pregnancy resolutions (birth weight) and Hanushek's (1992) study of the trade-off between the number of children and their scholastic performance (achievement level).

${ }^{5}$ The same consideration applies to $\alpha$ as long as the stochastic process that determines $X$ is similar to (3). In the empirical analysis, we treat all inputs in $X$ and $C$ similarly.
} 
does not reduce to zero even under the largely arbitrary orthogonality conditions $\sigma_{e \eta}=\sigma_{q \eta}=\sigma_{q e}=0$, where $\sigma_{y w}=\operatorname{cov}(y, w)$, for $y, w=\eta_{i}, e_{i}, q_{i t}$, and $\sigma_{x}^{2}$ is the cross-sectional variance of $x, x=e, q$. While $a_{1}$ and $a_{2}$ may be assumed to be positive, $b_{1}$ and $b_{2}$ could be either positive or negative. Thus the direction of the bias cannot be established a priori.

Many of the endogeneity problems of the level estimates arise from the presence of different individual-specific fixed endowments, which are correlated with each other and with unobserved endogenous inputs. If mental health and all the other relevant variables at a previous time $t-1$ are also observed, then it is possible to concentrate on the mental health changes over the intervening period. That is,

$$
\Delta H=\alpha \Delta X+\beta \Delta C+\gamma \Delta Z+\Delta u
$$

where $\Delta y=y_{t}-y_{t-1}$ for any time-varying variable $y=H, X, C, Z$, and $u$. From (2) and (3), it follows that $\Delta u=a_{2} \Delta q+\Delta \varepsilon$ and $\Delta C=b_{2} \Delta q+\Delta v$. Thus the covariance between $\Delta C$ and the error term in (5) is given by

$$
\operatorname{cov}(\Delta C, \Delta u)=2 a_{2} b_{2}\left(\sigma_{q}^{2}-\sigma_{q q_{-1}}\right)
$$

where $\sigma_{q q_{-1}}=\operatorname{cov}\left(q_{i t} q_{i t-1}\right)$. Notice that the identification of $\beta$ remains problematic even if the unobserved endogenous inputs are not correlated over time, that is, $\sigma_{q q_{-1}}=0$. In this case, however, we have a clearer understanding of the source of the bias. If avoidance of stress, physical exercise, good diet and other unobserved inputs are positively correlated with $u_{i t}$ (i.e., $a_{2}>0$ ), and if the same inputs are negatively correlated with non-standard employment status $C_{i t}$ (i.e., $\left.b_{2}<0\right)$, then $\operatorname{cov}(\Delta C, \Delta u)<0$ and estimation of (5) will lead to downward-biased estimates of $\beta$. This means that if the true $\beta$ is positive we understate its positive effect on mental health, while if the true $\beta$ is negative we overstate its negative 
effect on $H$. Of course, if $b_{2}>0$ and $a_{2}>0$, then $\operatorname{cov}(\Delta C, \Delta u)>0$ and estimation of (5) will lead to upward-biased estimates of $\beta^{6}$

To address the issue of endogeneity, we could also turn to instrumental variables techniques (Rosenzweigh and Schultz 1983; Grossman and Joyce 1990). The data used in our empirical analysis below do not, however, contain convincing exogenous instruments for the variables included in $C$. A set of instruments commonly used by economists is given by lagged values of the endogenous variables, $C_{i t-1}$, which can be exploited in this context given the longitudinal nature of our data. But the level estimates of $\beta$ are again inconsistent, with $\operatorname{cov}\left(C_{i t-1}, u_{i t}\right)=a_{1} b_{0} \sigma_{e \eta}+a_{2} b_{0} \sigma_{q \eta}+a_{2} b_{1} \sigma_{e q}+a_{1} b_{2} \sigma_{e q_{-1}}+a_{1} b_{1} \sigma_{e}^{2}+a_{2} b_{2} \sigma_{q q_{-1}}$, and the direction of the bias is always difficult to sign. Similarly, one-period lagged differences, $\Delta C_{-1}=C_{i t-1}-C_{i t-2}$, cannot easily identify $\beta$. In fact, even under the conditions that the correlation of $q_{i t}$ does not change over time, i.e., $\mathrm{E}\left(q_{i t} q_{i t-k}\right)=\mathrm{E}\left(q_{i t-r} q_{i t-s}\right)$, for all $k, r$ and $s \geq 1$, with $r \neq s$, we find that $\operatorname{cov}\left(\Delta C_{-1}, \Delta u\right)=a_{2} b_{2}\left(\sigma_{q q_{-1}}-\sigma_{q}^{2}\right)$, whose sign depends again on $b_{2}$ and the relative magnitudes of $\sigma_{q}^{2}$ and $\sigma_{q q_{-1}}{ }^{7}$

If we lag the difference in endogenous inputs one period further and thus use $\Delta C_{-2}=$ $C_{i t-2^{-}} C_{i t-3}$, it is easy to show that the two-period lagged first differences do yield consistent

\footnotetext{
${ }^{6}$ An identical argument holds if the variation in unobserved inputs across individuals is greater than the correlation in unobserved inputs over time, i.e., $\sigma_{q}^{2}>\sigma_{q q_{-1}}$.

${ }^{7}$ It should be noticed that, in this case, the bias of $\beta$ has an opposite sign of that previously obtained with first differences (see expression (6)). This fact can be exploited to find economically meaningful bounds around the true value of $\beta$, as long as the estimates obtained from first differences and the estimates obtained from one-period lagged first differences are well determined. In the empirical analysis below, however, we could not successfully pursue this strategy because both sets of estimates (from first differences and from oneperiod lagged differences) were not precisely measured. Notice also that, if $\sigma_{q q_{-1}}=0$ and $a_{2}>0$, then the difference between the estimates obtained from one-period lagged differences and the estimates obtained from first differences is equal to $3 a_{2} b_{2} \sigma_{q}^{2}$, which can be used to gauge the sign of $b_{2}$. But the interpretation of such a difference becomes ambiguous when multiple unobserved inputs contained in $q$ have opposite effects on the same form of non-standard employment $C$ (see equation (2)).
} 
estimates of the $\beta$ parameters, i.e., $\operatorname{cov}\left(\Delta C_{-2}, \Delta u\right)=0$, as long as the following orthogonality assumptions hold:

$$
\sigma_{q q_{-2}}=\sigma_{q q_{-3}}=\sigma_{q_{-1} q_{-2}}=\sigma_{q_{-1} q_{-3}}=0
$$

Three comments are in order. First, the identification of $\beta$ relies on rather strong restrictions on the process governing the temporal path of the unobserved inputs contained in $q$ (see conditions (7)). Second, in this two-period lagged first difference model, changes in employment-specific inputs, $\Delta C_{-2}$, occur two periods before the change in mental health, $\Delta H$, arguably a long period of time. But this time gap is necessary to remove the crosssectional variations in unobserved inputs from the relationship between observed inputs and error components. The orthogonality assumptions (7) are then required to eliminate potential intertemporal correlations in $q$. Third, the fixed-effects estimators recover estimates of $\beta$ only through the subset of individuals who move between standard and nonstandard jobs. This subset is likely to include both individuals who have a greater disutility from non-standard employment (or higher returns to standard employment) and unwillingly move into non-standard jobs and individuals who have stronger tastes for non-standard employment and optimally choose to be employed in non-standard jobs. If the health endowment and earnings endowment are positively correlated (i.e., $\operatorname{cov}\left(\eta_{i}, e_{i}\right)>0$ ) and the earnings endowment negatively affects $C$ (i.e., $b_{0}<0$ ), the former group of workers will be characterised by a negative effect of $C$ on $\mathrm{H}(\beta<0)$ while the latter group will be characterised by a positive effect $(\beta>0)$. The net effect will depend on the composition of the population under study. This is the main reason why, in our empirical analysis, we partition the sample by age and education groups.

This analytical framework motivates a straightforward empirical strategy. We first estimate an ordinary least squares (OLS) model as specified in (1). Although the OLS 
estimates are biased, they provide a useful benchmark. Second, we estimate a firstdifferenced fixed-effects production function equation (FE) as specified in equation (5). For these estimates, which are again inconsistent, we have a better understanding of the potential sources of bias. Finally, we estimate a two-period lagged first difference model $(\mathrm{FE}(-2))$, that is,

$$
\Delta H=\alpha \Delta X_{-2}+\beta \Delta C_{-2}+\gamma \Delta Z_{-2}+\Delta u
$$

This model, under the orthogonality conditions (7), identifies the parameters $\beta$ (and $\alpha$ ). The variables in $C, X$ and $Z$ are the same in (1), (5) and (8), except that the FE and FE(-2) models cannot identify time-invariant variables (such as, education and cohort of entry in the labour market). ${ }^{8}$ All the variables used in estimation are described in the next section.

\section{Data}

The preceding framework implies that to estimate the effect of non-standard employment on workers' mental health requires data that contain detailed longitudinal information on individuals' employment patterns and psychological wellbeing. To implement the FE(-2) model, the data must also provide at least four consecutive observations on the same workers. The data used in our empirical analysis come from the first seven waves of the British Household Panel Survey (BHPS), conducted over the period 1991-1997. The BHPS collects information on a nationally representative random sample of private households in Britain, with interviews first conducted during the autumn of 1991 and annually thereafter. ${ }^{9}$

\footnotetext{
${ }^{8}$ Kerkhofs and Lindeboom (1997) use a two-step procedure, in which estimates of the fixed effects from the first differenced equation are regressed on time-invariant variables. With this procedure they can retrieve the parameters of time-invariant variables that are swept from the estimation along with the fixed effects. See Jones (2000) for a discussion of this method.

${ }^{9}$ The achieved wave 1 sample covered 5,500 households and corresponds to a response rate of about 74 percent of the effective sample size. At wave 1, about 92 percent of eligible adults, i.e., almost 10,000 individuals, provided full interviews. The same individuals are re-interviewed each successive year, and if they split off from their original households to form new households all adult members of these households are also interviewed. Similarly, children in the original households are interviewed when they reach 16 years
} 
Our analysis is based on the subgroup of men and women who were born after 1936 (thus aged at most 60 in 1997), who reported positive hours of work, who provided complete information at each of the interview dates, who left school and were employed (either parttime or full-time) at the time of the survey, and who were not in the armed forces or selfemployed. ${ }^{10}$ We have an unbalanced longitudinal sample of 1,740 men and 1,981 women, with 11,166 and 12,808 person-wave observations for men and women respectively.

The dependent variable in the OLS model is a well-known mental health indicator, which is derived from the General Health Questionnaire (GHQ) and is widely used in the medical literature (Goldberg 1972). This measure converts the answers to twelve health questions (measured on a scale running between 1 and 4 ) to a single index running from 0 to 36 , with 0 representing the highest level and 36 the lowest level of psychological health. ${ }^{11}$ The index is obtained after summing the answers to the twelve questions and scaling each of them from 0 to 3 (rather than 1 to 4$).^{12}$

The first row of Table 1 presents means and standard deviations of the GHQ index for all male and female workers. On average, women report higher values of the GHQ

of age. Thus, the BHPS sample remains broadly representative of the population of Britain as it changes over time. Of those interviewed in the first wave, 88 percent were successfully re-interviewed at wave 2 (Autumn 1992), and subsequent wave-on-wave response rates have consistently been above 95 percent. Problems of differential attrition are therefore likely to be relatively modest. Detailed information on the BHPS can be obtained at http://www.iser.essex.ac.uk/bhps/doc/index.html.

${ }^{10}$ Although our restriction to employees may introduce some form of sample selection and thus potentially bias our estimates, it is designed to make the subsamples of men and women as comparable as possible in terms of their attachment to the labour market. An important extension of our analysis is the inclusion of the self-employed and the unemployed. This is left for future research.

${ }^{11}$ Information on psychological wellbeing is measured in comparison with 'usual' conditions. It is elicited by questions regarding the way the respondent has been feeling over the last few weeks. The exact phrasing is: "Have you recently ... (felt under strain, depressed, etc.)?". The twelve subjective indicators are: (i) loss of concentration; (ii) loss of sleep; (iii) playing a useful role; (iv) capable of making decisions; (v) constantly under strain; (vi) problems overcoming difficulties; (vii) enjoy day-to-day activities; (viii) ability to face problems; (ix) unhappy or depressed; (x) losing confidence; (xi) believe in self-worth; (xii) general happiness. See Cox et al. (1994).

${ }^{12}$ Goldberg (1972) has shown that trained psychiatrists are likely to make a diagnosis of a mental disorder when at least four symptoms of distress are identified on the GHQ. For this reason the GHQ is often used as a dichotomous indicator with a cut-off point at a score of 4 when a 12-point scale is adopted (see Frank and Gertler 1991). To simplify our estimation, however, we use the GHQ as a numerical (continuous) index rather than as a dichotomous indicator. 
measure than men do, i.e., they have a lower level of psychological wellbeing. The difference of 1.35 points is significant at any statistical level. Figure 1 shows the entire distributions of the GHQ index by gender. For men and women, the figure clearly shows that approximately 80 percent of the observations are contained between values of 5 and 15 of the index, with the women's distribution having a somewhat fatter right tail. The dependent variable in the FE and FE(-2) models is the change in the GHQ index between waves $t$ - 1 and $t(t=1992, \ldots, 1997)$. Its distribution by gender is reported in Table 2 and shown in Figure 2. Just over 80 percent of the changes for women and almost 90 percent of the changes for men lie between -6 and 6 , suggesting that annual variations in mental health are usually small. ${ }^{13}$

The employment-specific inputs, $C_{i t}$, are the endogenous or behavioural variables assumed to have a direct technical relationship with mental health, as expressed in (1), (5) or (8). The BHPS data allow us to distinguish four types of non-standard employment. The extent to which men and women are distributed across them is shown in Table 1. The table also reports means and standard deviations of the GHQ index by type of employment. The first type of non-standard employment involves non-standard contracts, which we can further break down into seasonal or casual work and work done for a fixed period of time. The standard (base) category is working on a permanent contract. About 3 percent of all workers are on fixed-term contracts, while 4 and 6 percent of men and women are in seasonal/casual jobs. The second type of employment involves non-standard places of work, and distinguishes between those who work at home, those who work driving and travelling and those who work in more than one place (for a single job). The base category is working at the employer's premises. A larger fraction of men have a job in non-standard

\footnotetext{
${ }^{13}$ The inference based on the GHQ index is not likely to be contaminated by sample selection bias as
} 
places, particularly working in a job that requires driving/travelling and working in more than one place. The third type of non-standard employment is about working times, which separately identifies those who work mornings only, those who work either afternoons, or evenings, or nights or both lunch and evening ('other parts of the day'), those who have varying patterns and those who work in rotating shifts. The standard category for this type of employment is working 'during the day'. About one-quarter of men and one-third of women work during non-standard times. While 13 percent of men are in jobs that involve rotating shifts, 9 percent of women work in the morning and another 10 percent work during other parts of the day. The fourth type of non-standard employment refers to the number of hours of work. We distinguish between those who work 1 to 15 hours per week ('mini-jobs'), those who work between 16 and 29 hours per week and those who work more than 48 hours per week. The standard category is working between 30 and 48 hours per week. ${ }^{14}$ Almost 4 in 10 women work less than 30 hours per week, whereas nearly 3 in 10 men work more than 48 hours per week. These four types of employment are not mutually exclusive, that is, a worker may be on a fixed-term contract, have varying patterns of work, and work more 48 hours per week. In estimating the OLS model, we use these measures as our employment-related inputs. In estimating the FE and FE(-2) models, we use the changes in such inputs, i.e., entry into, exit from and stay in, say, a seasonal/casual job or a fixed-term contract. ${ }^{15}$

discussed in Frank and Gertler (1991). This is because the GHQ index in the BHPS is a 'population-based' (rather than 'utilisation-based') measure of mental distress.

${ }^{14}$ The choice of these cutoffs is motivated by current institutional settings in Britain. Workers in 'mini-jobs' (and low income) are potentially eligible for the Income Support and Jobseeker's Allowance benefits (Iacovou and Berthoud, 2000). Those working between 16 and 29 hours are part-timers comparable to the workers in 'half-time' jobs defined in Hakim (1997). Those working long hours are the target of recent European Union policy initiatives (such as the 1998 European Working Time Directive) that aim to reduce the number of hours worked in a week below 48 (Neathey and Arrowsmith 1999).

${ }^{15}$ In the estimation, because of sample size problems and tractability, we do not distinguish between the (standard or non-standard) employment states preceding an entry, nor do we distinguish between the (standard or non-standard) employment states following an exit. 
The Appendix Table A1 reports the sample means of all the other inputs, $X$, and exogenous variables, $Z$, used in the empirical analysis. Male and female workers are equally distributed across four age groups (16-25, 26-35, 36-45, 46-60, where 'age' refers to the age at the start of the panel). A larger proportion of women than men are separated, divorced or widow, while a larger proportion of men have never been married. The distribution of dependent children by age is fairly similar by gender. Men and women are also similarly distributed by housing tenure (three groups: social housing, rented accommodation, and owner), region of residence (seven regions) and cohort of entry into the labour market (five cohorts). Relatively more women have less than O-level/GCSE qualifications, while more men have higher vocational or university degrees. ${ }^{16}$ Men also have more full-time work experience (17 years versus 10 years), but women have a larger part-time work experience (almost 5 years versus 3 months). Workers are grouped in ten industries obtained from the Standard Industrial Classification. Of all observations on women, almost three-fifths are in services (including banking), and another quarter are in distribution and trade. Conversely, men are more widespread across industries. We distinguish nine occupations derived from the Standard Occupational Classification. Men are concentrated in managerial, craft and semi-skilled (plant and machine operatives) occupations. Women, instead, are predominantly in clerical, secretarial and personal service occupations. A larger fraction of men than women work in the private sector, while more women are in the local government sector. We also stratify workers by firm size (eight categories): almost two-fifths of men and half of women are in firms with fewer than

\footnotetext{
${ }^{16}$ Those who completed their compulsory education in 1988 (born 1971-1972) were the first to study for the General Certificate of Secondary Education (GCSE) qualification; earlier cohorts would have studied for Olevel qualifications. For readers who are not familiar with the British education system, 'O(Ordinary)-level' and GCSE roughly corresponds to a high school diploma; 'A(Advanced)-level' corresponds to education beyond higher school but short of a university degree. 'Higher vocational degree' includes qualifications such
} 
50 employees, and about 10 percent of men and women are in establishments with more than 1000 workers. A slightly greater proportion of men are in union-covered jobs. Both men and women smoke an average of 4 cigarettes a day. ${ }^{17}$ Aside from age, all these variables are endogenous inputs to the production of workers' mental health. The only other exogenous variable is given by local labour market conditions, measured by the ratio of unemployment stock to vacancies stock. The geographic unit of this measure is given by 306 matched job centres (providing information on the vacancies stock) and travel-to-work areas (providing information on the unemployment stock). ${ }^{18}$

\section{Results}

\subsection{Basic estimates}

Tables 3-6 report the estimated effects on the GHQ index of non-standard contracts, places, times and hours of work, respectively, Each table presents the OLS, FE, and FE(-2) estimated obtained using specifications (1), (5), and (8) respectively. ${ }^{19}$ For each type of non-standard employment, the effect is separately estimated for men and women. ${ }^{20}$

From the FE(-2) male estimates in Table 3, we detect a worsening of mental health status by about 1.5 points for those who enter in seasonal/casual jobs. Leaving such jobs

as teaching and nursing qualifications, City and Guilds certificates, Higher National Certificate/Diploma, and University Diploma. Some of these qualifications may not require A-level qualifications.

${ }^{17}$ The means computed on the subsample of smokers are 16 and 15 cigarettes a day for men and women, respectively. The corresponding number of person-wave observations over which such figures are computed is 2,933 and 3,733 .

${ }^{18}$ We are grateful to Tim Butcher and Mark Taylor for constructing the matched BHPS and NOMIS (National On-line Manpower Information Service) travel-to-work area file that is needed for this variable.

${ }^{19}$ We estimate separate regressions for each type of non-standard employment since this allows us to identify which aspects of employment flexibility are more likely to affect workers' mental health (either positively or negatively). The extent of the overlap between different types of non-standard employment would make this identification more difficult (Francesconi 2000). Because a greater value in the GHQ index corresponds to a lower level of mental health, a positive (negative) estimate means a reduction (increase) of mental health status. For simplicity, the estimates of the other inputs and exogenous variables are not reported. They can be obtained from the authors upon request. 
significantly improves mental health by about 1.2 GHQ points, according to the FE estimates. These results are consistent with the evidence presented in Booth et al. (2000), which suggests that seasonal/casual workers report lower levels of job satisfaction, are less likely to receive on-the-job training and have lower wage profiles than workers in permanent jobs. If these labour market outcomes are also associated with mental health, then movements in and out of seasonal/casual jobs are likely to produce the estimated results. Conversely, the transitions around fixed-term contracts do not significantly affect workers' psychological wellbeing. Notice, however, that the OLS estimates detect an improvement of mental health for male workers who are on a fixed-term contract. This association may partly reflect the relationship between experience of work in such contracts and individual endowments. In the case of women, the $\mathrm{FE}(-2)$ estimates show a mild health-worsening effect of leaving seasonal/casual jobs and a mild health-enhancing effect of staying in such jobs. Both effects are significant only at the 10 percent level. Regardless of the model, no additional effect can be detected.

Starting a job that involves working in more than one place improves men's psychological health by two-thirds of a point of the GHQ score (Table 4, FE(-2) estimates). There is no evidence of other significant associations. From the FE estimates, the largest positive association (but only significant at the 10 percent level) emerges for men who start working at home. They experience a worsening of mental health by 1.4 points. The model developed in Section 2 implies that, if $a_{2}>0, b_{2}<0, \sigma_{q}^{2}>\sigma_{q q_{-1}}$, and the true parameter were positive, this effect is then underestimated. Leaving jobs that involve working in more than one place decreases women's psychological wellbeing by about one GHQ point (FE(-2)

\footnotetext{
${ }^{20}$ While interpreting our results, it is important to keep in mind our sample restriction to people who are employed at the time of interview. Clearly, this may have selected a special group of men and women with possibly high levels of mental health (low scores in the GHQ index).
} 
estimates). But this effect is not well determined. It is entering into such jobs that improves women's health by almost one point, according to the FE estimates. For both men and women, the evidence obtained from the OLS model does not indicate any specific pattern of the association between non-standard places of work and the GHQ index.

The OLS estimates in Table 5 indicate a negative correlation between working on rotating shifts and the GHQ index for men. But this association disappears when endowment heterogeneity and self-selection of unobserved inputs are taken into account. The FE(-2) estimates reveal that entering into a job that involves working only in the mornings greatly improves the GHQ index by almost 2.5 and 1.2 points for men and women, respectively. Although less than 2 percent of male workers are employed in such jobs, 9 percent of women may potentially experience this effect. The FE estimates, however, cannot uphold this finding. But if $a_{2}>0, b_{2}<0, \sigma_{q}^{2}>\sigma_{q q_{-1}}$, and the true parameter were negative (as found by $\mathrm{FE}(-2)$ ), the FE model would provide an upward-biased estimate of the true effect. This is confirmed by the fact that the FE estimates are greater than the corresponding FE(-2) estimates for both men and women. The FE model detects instead significant health effects for women who move out of working mornings only (improvement) and varying time patterns (deterioration).

Table 6 clearly shows that the only significant effect of non-standard hours emerges for men who stay in mini-jobs (fewer than 16 hours per week). They are predicted to face a reduction in their psychological wellbeing by nearly 1.2 GHQ points, and this effect is also detected by the estimate obtained from the FE model. But other types of non-standard hours of work (including long hours) do not significantly affect men's mental health. In the case of women, flexible hours of work appear to have no substantial effect on the GHQ index. This finding is remarkable because nearly 40 percent of women in mini-jobs and 
half-time jobs have levels of job satisfaction that typically differ from those of women in full-time standard jobs. ${ }^{21}$ To the extent that there is a relationship between changes in the GHQ index and the probability of divorce, our results are consistent with those reported by Johnson (1999), which show a negligible effect of long hours of work on divorce probabilities.

In sum, the four types of non-standard employment analysed in this study (nonstandard contracts, places, times, and hours of work) have limited effects on workers' psychological wellbeing. Not only does this hold for both men and women, but the lack of widespread and significant effects is also prevalent across fixed-effects models, which differ in the restrictions needed to identify the parameters of interest. As noted in Section 2, the FE and FE(-2) models identify the estimates of $\beta$ through the subset of workers that move in and out of non-standard jobs. This subset may include both individuals who have strong tastes for non-standard employment and individuals who have a high disutility from it. Because these two groups of workers are characterised by offsetting effects of $C$ on $H$ (provided that, ceteris paribus, earnings and health endowments are positively correlated), a possible interpretation of our results is that the transitions in and out of non-standard employment are roughly equally made up by both groups of workers. The net estimated effect is thus small and insignificant. With the notable exception of non-standard contracts for men, a similar lack of effects also emerges with a conventional (cross-sectional) OLS

\footnotetext{
${ }^{21}$ Cross-sectional ordered probit regressions of job satisfaction on non-standard hours reveal that, relative to women who work 30-48 hours per week, women in mini-jobs and in half-time jobs have a significantly higher overall job satisfaction, and a higher satisfaction in terms of total pay, relations with the boss and hours worked. The regressions also control for a set of standard determinants of job satisfaction (e.g., age, education, number of children by age, work experience, occupation, industry, region of residence, firm size, sector, union coverage, and local labour market conditions). Each aspect of job satisfaction is measured on a scale from 1 to 7, where a value of 1 corresponds to "not satisfied at all" and a value of 7 corresponds to "completely satisfied". These results are available from the authors upon request.
} 
model, which cannot be used to derive causal conclusions because it does not account for the correlations of health outcomes with unobserved inputs and endowments.

\subsection{The relationship between health endowment and non-standard employment behaviour}

Economic theory does not provide a straightforward prediction of how the choice of nonstandard types of employment varies with the exogenous components of individual mental health in the stochastic process (3), without information on preference orderings and health technology. To gauge the sign and the magnitude of the relationship between flexible employment behaviour and health endowment is therefore an empirical issue.

In addition to an error component that was unforeseen by the worker and by assumption does not affect his/her labour market behaviour, the residuals from the FE(-2) and FE production function estimates, conditioned on the inclusion of all other inputs, contain both the exogenous endowment effect (through $e$ and $\eta$ ) and the unobservable inputs effect (through $q$ ). Thus, regressions of the employment-specific inputs chosen by the workers, $C$, on the $\mathrm{FE}$ and $\mathrm{FE}(-2)$ production function residuals provide estimates that cannot disentangle the effect of the endowments from the effect of other unobserved inputs on a worker's non-standard employment behaviour. ${ }^{22}$

Table 7 contains the estimates (and standard errors) for each non-standard employment input computed from the FE and the FE(-2) models. ${ }^{23}$ Without exception, these estimates reveal that the non-standard employment behaviour among British workers

\footnotetext{
${ }^{22}$ As argued by Rosenzweig and Schultz (1983), these regressions should yield the correct sign of the relationship, even though the presence of measurement error in the calculated residuals biases the effect of the health endowment toward zero.

${ }^{23}$ The estimates are obtained from 36 probit regressions (one for each of the elements of $C$ ) because all the employment-related inputs of interest are binary variables. In each regression the dependent variable is one of the non-standard employment inputs and the only explanatory variable are the $\mathrm{FE}$ or $\mathrm{FE}(-2)$ residuals (obtained from either equation (5) or equation (8)). To ease the interpretation, the table expresses the estimates in marginal effects evaluated at the sample means. The results obtained from a linear probability model are identical to those reported here.
} 
does not significantly vary with their health endowments and their unobserved inputs. This partly explains why the OLS model provides estimates that are largely comparable to those obtained from the FE and FE(-2) models in Tables 3-6. This result may arise because neither health endowments nor unobservable inputs have a genuine effect on workers' choice of non-standard employment. But it may also arise because they have an offsetting impact on individuals' labour market behaviour. For example, non-standard jobs may be negatively correlated with health endowment and positively correlated with unobserved health inputs (i.e., $b_{1}<0$ and $b_{2}>0$ in equation (3)). Therefore, if workers with less favourable endowments choose to make unobserved healthy decisions (such as good diet and balanced physical training), their probabilities of being in, exiting from and entering into a non-standard job are likely to be largely unaffected. This is also true if betterendowed workers choose less healthy inputs. These examples suggest that population health heterogeneity may still have a critical effect on the observed patterns in labour market behaviour. However, we fail to measure this effect as long as individuals 'compensate' their unfavourable (favourable) endowments with healthy (unhealthy) inputs.

\section{Sensitivity analysis}

Even though the effects for the entire workforce are arguably small, there may be powerful interactions between age and non-standard types of employment or between education and non-standard forms of employment, which directly affect the relationship with workers' psychological wellbeing. ${ }^{24}$ Table 8 shows a positive relationship between age (at the start

\footnotetext{
${ }^{24}$ Francesconi (2000) shows some systematic patterns of non-standard employment by age and education groups for a similar sample of British workers. In general, non-standard types of employment are more common among younger workers. The distribution of flexible work by education is, instead, more heterogeneous, with some types of non-standard employment having a large proportion of highly qualified workers and other types having a large proportion of workers with no qualifications. For example, more than one quarter of men and women on fixed-term contracts has a university degree. A large proportion of those in
} 
of the panel) and GHQ scores, that is, younger workers generally report a greater level of psychological wellbeing than older workers. With only one exception, these age (or cohort) differences are highly significant. The relationship between education and mental health is more complex. ${ }^{25}$ Relative to the other education groups, men with O-level/GCSE qualifications report the highest level of psychological fitness, with mental health differences being significant between education groups that are two or more rungs apart from each other. Among women, it is those with O-level/GCSE qualifications or A-level qualifications that report the highest level of mental health (i.e., the lowest GHQ score), and their health differences with the women in the other two education groups are always significant. To check whether these age and education differences in mental health are related to the patterns of non-standard employment and whether they are robust to the inclusion of the other inputs and exogenous variables, we estimate the OLS, FE and FE(-2) models for three age groups (aged less than 30, aged 30 to 44, and aged 45 to 60 ) and four education groups (less than O-level/GCSE qualification, O level/GCSE, A level, more than A level) and for men and women separately. ${ }^{26}$ Notice that by defining more homogenous groups of workers, these stratifications by age and education are also likely to reduce the preference and constraint variations that characterise the subset of individuals moving in and out of non-standard employment (see Section 2).

mini-jobs have lower levels of education, while, of the women working more than 48 hours a week, about two-thirds have qualifications above A level. Bebbington et al. (1998) and Pevalin (2000) document the relationship between age and mental health; Bebbington et al. (2000) document the relationship between mental health and social class, of which education can be taken as a proxy measure.

${ }^{25}$ To simplify the analysis, we only focus on four education groups, by combining workers with no qualification with those with less than O-level (GCSE) qualifications and by combining workers with higher vocational degrees with those holding university and higher degrees.

${ }^{26}$ It is worthwhile noting that both age at the start of the panel (or cohort) and education are time-invariant factors, which cannot be identified in the FE and FE(-2) models. Using the procedure outlined in Kerkhofs and Lindeboom (1997), we have regressed the FE and FE(-2) mental health production function residuals on age at start of the panel, education, and cohort of entry into the labour market, for each of the four types of non-standard employment and for men and women separately. The estimates from these regressions show no effect for age, education, and labour market cohort. But the relationship between such time-invariant factors 


\subsection{Age groups $^{27}$}

Tables A2-A5 contain the results for the cohort-based sample partition. The worsening of mental health for men who enter into seasonal/casual jobs reported in Table 3 is primarily accounted for by the effect experienced by workers aged less than 30 (Table A.2a). This group of workers also shows a worsening of psychological wellbeing if they stay in seasonal/casual jobs and an improvement of mental fitness if they keep working on fixedterm contracts. However, these two latter effects are significant only at the 10 percent level. But non-standard contracts do not have any relevant impact on the GHQ index for men in the other two age groups. Similarly, women aged 30 or more do not show any conspicuous variation in mental health (Table A.2b). The only significant impact occurs for women aged less than 30, who experience an improvement of about 1.7 points in the GHQ index when they enter into seasonal/casual jobs. This effect could not be detected by estimating the sample as a whole, because it is confounded by opposite (and insignificant) effects for women aged 30 or more.

Interestingly, the lack of effects on mental health for women aged 30 or more persists even in the case of non-standard places (Table A.3b) and in the case of nonstandard times (Table A4.b). The health-reducing effect of leaving a job that involves working in more than one place (Table 4) and the health-enhancing effect of entering into a job that involves working in the mornings only (Table 5) are mainly driven by the effects estimated for the youngest group of women. Both these effects are large (around 2.3 GHQ points in absolute value) and well determined. Conversely, in the case of men, starting working in more than one place improves the GHQ score for workers aged 30-44 and aged 45 or more. These are the effects that drive the negative correlation estimated for the whole 
sample of men (see Table 4). In the case of non-standard times, the health improvement due to entering into a job that involves working in the mornings only and reported in Table 5 can be accounted for by the large impact shown by men aged less than 45 . Older men experience a sizeable, significant improvement in mental health of about 5 points when they start working in 'other parts of the day' (including afternoons only, evenings only and nights only). We fail to detect such an effect for the entire sample primarily because of the large standard errors with which the effects for the other two age groups are measured.

The fact that the only significant effect of non-standard hours for men in the whole sample (Table 6) emerges in the case of workers who stay in mini-jobs (fewer than 16 hours per week) is driven by the estimates obtained for the subgroup of workers aged less than 30 (Table A.5a). Although entering into mini-jobs heavily increases the psychological distress of workers aged 45 or more, this effect is not statistically significant (presumably because of the small sample of workers involved in such a transition). ${ }^{28}$ For women, the health effects of non-standard hours are spread across the three age groups and are never highly significant (Table A.5b). The estimates show a fall of mental health by about 2 points $(t$-ratio $=1.903)$ in the case of women aged 45 or more when they enter into minijobs. Workers in the same age group also experience a deterioration of mental health by 1.6 points $(t$-ratio $=1.897)$ when they leave half-time jobs $(16-29$ hours per week $)$

\subsection{Education groups}

Tables A6-A9 contain the results for the stratification by education. In the case of men, both workers with qualifications short of O level/GCSE or with no qualification and

\footnotetext{
in endowments and unmeasured health inputs.

${ }^{27}$ The comments in this and the next subsections are limited to the estimates obtained from the FE(-2) model.

${ }^{28}$ In fact, our data contain only 7 such transitions, which account for about 0.7 percent of the observations used in estimation.
} 
workers with qualifications above A-level face a health reduction when they start working in seasonal/casual jobs (Table A.6a). These effects are large (almost 3 GHQ points) and significant at the 5 percent level. We find a number of other effects. In particular, workers holding A-level qualifications experience a deterioration (of the order of 2.5-3 points) in their psychological health when they leave jobs involving either type of non-standard contract. They also have health gains of nearly 4 points if they keep working on fixed-term contracts. But getting a job on fixed-term contracts reduces the mental health of workers in the highest educational group. The mild health deterioration found for women who leave seasonal/casual jobs in the whole sample appears to be driven by the effect on women in the highest educational category (Table A.6b). On the other hand, entering into either type of non-standard jobs substantially improves the psychological wellbeing of women holding A-level qualifications.

There is evidence of very few significant effects on mental health across education groups in the case of non-standard places of work (Tables A.7a and A.7b). The large and well-measured effect for men with O-level qualifications and with higher vocational and university degrees who start working in more than one place (improvements of 1.7 and 1.0 GHQ points, respectively) drives the effect estimated for the entire sample of men. Other significant effects are those for men with A-level qualifications who stop working in more than one place (a deterioration of 1.6 points), and for women with A-level qualifications leaving jobs that involve driving or travelling (an improvement of more than 5 points). We cannot detect any relevant difference across education categories in the effect of nonstandard working times on mental wellbeing for men (Table A.8a). For women with less than O-level qualifications, instead, it is starting a job on rotating shifts that worsens mental health by about 2.3 points. In addition, women with A levels experience a rise in the 
GHQ index by nearly 4 points when they stop working in 'other parts of the day'. The health-enhancing effect detected in the whole sample for workers who start working in the mornings only (Table 5) is accounted for by the effects experienced by women with less than O-level qualifications and by women with A levels (although this last effect is not statistically significant).

Regardless of the schooling level, there is no significant effect of non-standard hours of work on mental health among men (Table A.9a). The reduction of 3.3 points in the GHQ score for women with A-level qualifications who stop working more than 48 hours per week drives the small health improvement observed in the whole female sample. We find, instead, that starting working long hours deteriorates the mental health of women with O-level qualifications by almost 1.9 points. These two results jointly suggest that some groups of women may face psychological distress in combining family commitments with long hours of work (see Schor 1992; Presser 2000). We also find that women with more than A-level qualifications experience a health reduction of 3.3 GHQ points when they leave mini-jobs.

\section{Conclusions}

In this paper, we examine the relationship between non-standard types of employment (non-standard contracts, places of work, times of the day, and weekly hours) and mental health in Britain during the 1990s using data from the first seven waves of the BHPS, 1991-1997. A simple analytical framework based on the specification of an individual's mental health production function allows us to address the issue of the endogeneity of unobserved inputs that are potentially correlated with exogenous health (and earnings) endowments. Not only are least squares estimates inadequate to identify the effect of 
flexible working arrangements on mental health, but also fixed-effects estimates fail, as long as there are self-selected unobserved health inputs that affect labour market behaviour and health status and vary across individuals and over time. Two-period lagged first differences, however, yield consistent estimates of the effect of non-standard employment on psychological wellbeing under some orthogonality conditions on the process governing the dynamic path of the unobservable inputs. Because such conditions are strong, even these estimates must be taken with some caution.

There is evidence of only a limited effect of all types of flexible employment on the GHQ scores of both men and women. We also find that the non-standard employment behaviour among British workers does not significantly vary with their health endowments and their unobserved inputs. This does not necessarily imply that endowments and unobserved inputs are inconsequential to workers' labour market decisions, because they may have offsetting effects.

Stratifying the sample by age (or birth cohort) and education reveals some large and significant relationships between non-standard employment and mental health that are confounded in the sample as a whole. The cohort-based partition shows that the health effects for workers aged less than 30 are particularly strong in the case of non-standard contracts and non-standard hours for men, and all types of non-standard employment for women (with the exception of hours). The mental health status of men and women aged 45 or more is especially responsive to non-standard times and non-standard hours of work, respectively. The relationship between non-standard types of employment and mental health across education groups is more complex, suggesting perhaps that the extent of heterogeneity is greater across education groups than across age groups. Highly educated women (holding A-level qualifications or more) and men from all the education groups 
tend to experience some significant (positive or negative) health changes due to contract and place-of-work flexibility. Women's GHQ scores are also sensitive to flexible time and flexible hours arrangements, regardless of their position in the education distribution. The fact that some of these effects are positive and others are negative means that they "cancel out' when we estimate these relationships for the entire sample of women.

An important extension of this paper is to include in estimation the entire population and not just the subsample of employees. This extension is especially desirable if some of the excluded individuals experience frequent transitions into and out of nonstandard employment (such as, the unemployed or the self-employed). In fact, the increasingly complex contractual situation in the labour market may mean that some unemployed (or self-employed) who get a non-standard job experience differential job security and career prospects compared to others who are always in the labour market and only occasionally experience some form of non-standard work (Strandh 2000; Arulampalam 2000; Steward 2000). As these different exit/entry routes imply different life styles, we expect that they have a different impact on people's mental health. 


\section{References}

Arulampalam, W. (2000) "Is Unemployment Really Scarring?" Mimeo, University of Warwick.

Bartel, A. and P. Taubman (1986) "Some economic and demographic consequences of mental illness." Journal of Labor Economics, 4, 243-256.

Bebbington, P., G. Dunn, R. Jenkins, G. Lewis, T. Brugha, M. Farrell, H. Meltzer (1998) "The influence of age and sex on the prevalence of depressive conditions: report from the National Survey of Psychiatric Morbidity." Psychological Medicine, 28, 919.

Bebbington, P., T. Brugha, H. Meltzer, M. Farrell, C. Ceresa, R. Jenkins, G. Lewis (2000) "Psychiatric disorder and dysfunction in the UK National Survey of Psychiatric Morbidity." Social Psychiatry and Psychiatric Epidemiology, 35, 191-197.

Bishai, D.M. (1996) "Quality time: How parents' schooling affects child health through its interaction with childcare time in Bangladesh." Health Economics, 5, 383-407.

Booth, A.L., M. Francesconi and J. Frank (2000) "Temporary jobs: Who gets them, what are they worth, and do they lead anywhere?" ISER Working Paper No. 2000-13, University of Essex, April.

Cox, D.R., R. Fitzpatrick, A.E. Fletcher, S.M. Gore, D.J. Spiegelhalter and D.R. Jones (1994) "Quality of life assessment: Can we keep it simple?" Journal of the Royal Statistical Society, Series A, 155, 353-393.

Dex, S. and A. McCulloch (1995) "Flexible employment in Britain: A statistical analysis", Equal Opportunities Commission, Research Discussion Series No. 15.

Ettner, S.L., R.G. Frank and R.C. Kessler (1997) "The impact of psychiatric disorders on labor market outcomes." Industrial and Labor Relations Review, 51, 64-81.

Francesconi, M. (2000) "Flexible employment in Britain during the 1990s." Employment Audit, forthcoming.

Frank, R.G. and P. Gertler (1991) "An assessment of measurement error bias for estimating the effect of mental distress on income." Journal of Human Resources, 26, 154- 164.

Frank, R.G. and T.G. McGuire (2000) "Economics and mental health.” In: A.J. Culyer and J.P. Newhouse (eds.), Handbook of Health Economics, vol. 1B, Amsterdam: North Holland.

Goldberg, D. (1972) The Detection of Psychiatric Illness by Questionnaire. London: Oxford University Press.

Grossman, M. (1972) "On the concept of health capital and the demand for health." Journal of Political Economy, 80, 223-255. 
Grossman, M. and T.J. Joyce (1990) "Unobservables, pregnancy resolutions, and birth weight production functions in New York City." Journal of Political Economy, 98, 983-1007.

Hamilton, V.H., P. Merrigan and E. Dufresne (1997) "Down and out: Estimating the relationship between mental health and unemployment." Health Economics, 6, 397406.

Hanushek, E.A. (1992) "The trade-off between child quantity and quality." Journal of Political Economy, 100, 84-117.

Hochschild, A.R. (1997) The Time Bind: When Work Becomes Home and Home Becomes Work. New York: Metropolitan Books.

Iacovou, M. and R. Berthoud (2000) Parents and Employment. Leeds: Department of Social Security, Research Report No. 107.

Jin, R.L., C.P. Shah and T.J. Svoboda (1995) "The impact of unemployment on health: A review of the evidence." Canadian Medical Association Journal, 153 (5), 529-540.

Johnson, J.H. (1999) "Do long hours contribute to divorce?" Unpublished paper, University of Illinois at Urbana-Champaign, November.

Jones, A.M. (2000) "Health econometrics." In: A.J. Culyer and J.P. Newhouse (eds.), Handbook of health economics, vol. 1A, Amsterdam: North Holland.

Kerkhofs, M. and M. Lindeboom (1997) "Age related health dynamics and changes in labour market status." Health Economics, 6, 407-423.

Link, B.G., H. Andrews and F.T. Cullen (1992) "The violent and illegal behavior of mental patients reconsidered." American Sociological Review, 57, 275-292.

Murphy, G.C. and J.A. Athanasou (1999) "The effect of unemployment on mental health." Journal of Occupational and Organizational Psychology, 72, 83-99.

Pevalin, D.J. (2000) "Multiple applications of the GHQ-12 in a general population sample: an investigation of long-term retest effects." Social Psychiatry and Psychiatric Epidemiology, forthcoming.

Presser, H.B. (1995) "Job, family, and gender: determinants of nonstandard work schedules among employed Americans in 1991." Demography, 32(4), 577-598.

Presser, H.B. (2000) "Nonstandard work schedules and marital instability." Journal of Marriage and the Family, 62(1), 93-100.

Rosenzweig, M.R. and T.P. Schultz (1983) "Estimating a household production function: Heterogeneity, the demand for health inputs, and their effects on birth weight." Journal of Political Economy, 91, 723-746.

Schor, J. (1992) The Overworked American: The Unexpected Decline of Leisure. New York: Basic Books. 
Stewart, M.B. (2000) "The Inter-related Dynamics of Unemployment and Low Pay", mimeo, University of Warwick.

Strandh, M. (2000) "Different exit routes from unemployment and their impact on mental well-being: the role of the economic situation and the predictability of the life course." Work, Employment and Society, 14(3), 459-479.

Theodossiou, I. (1998) "The effects of low-pay and unemployment on psychological wellbeing: a logistic regression approach." Journal of Health Economics, 17, 85-104.

Wadsworth, M.E.J., S.M. Montgomery and M.J. Bartley (1999) "The persisting effect of unemployment on health and social well-being in men early in working life." Social Science \& Medicine, 48, 1491-1499. 

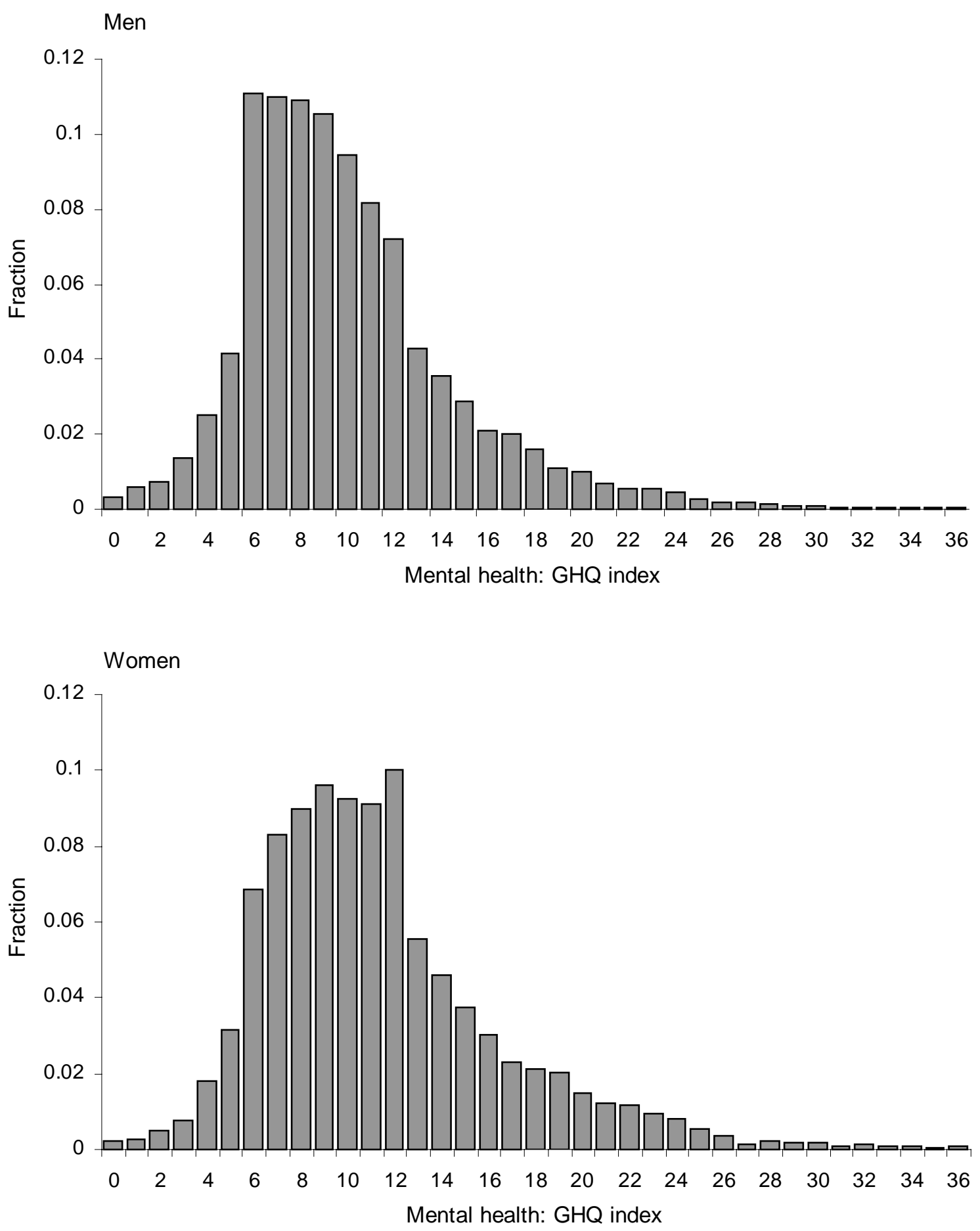

Figure 1: The distribution of mental health (GHQ index) by gender 

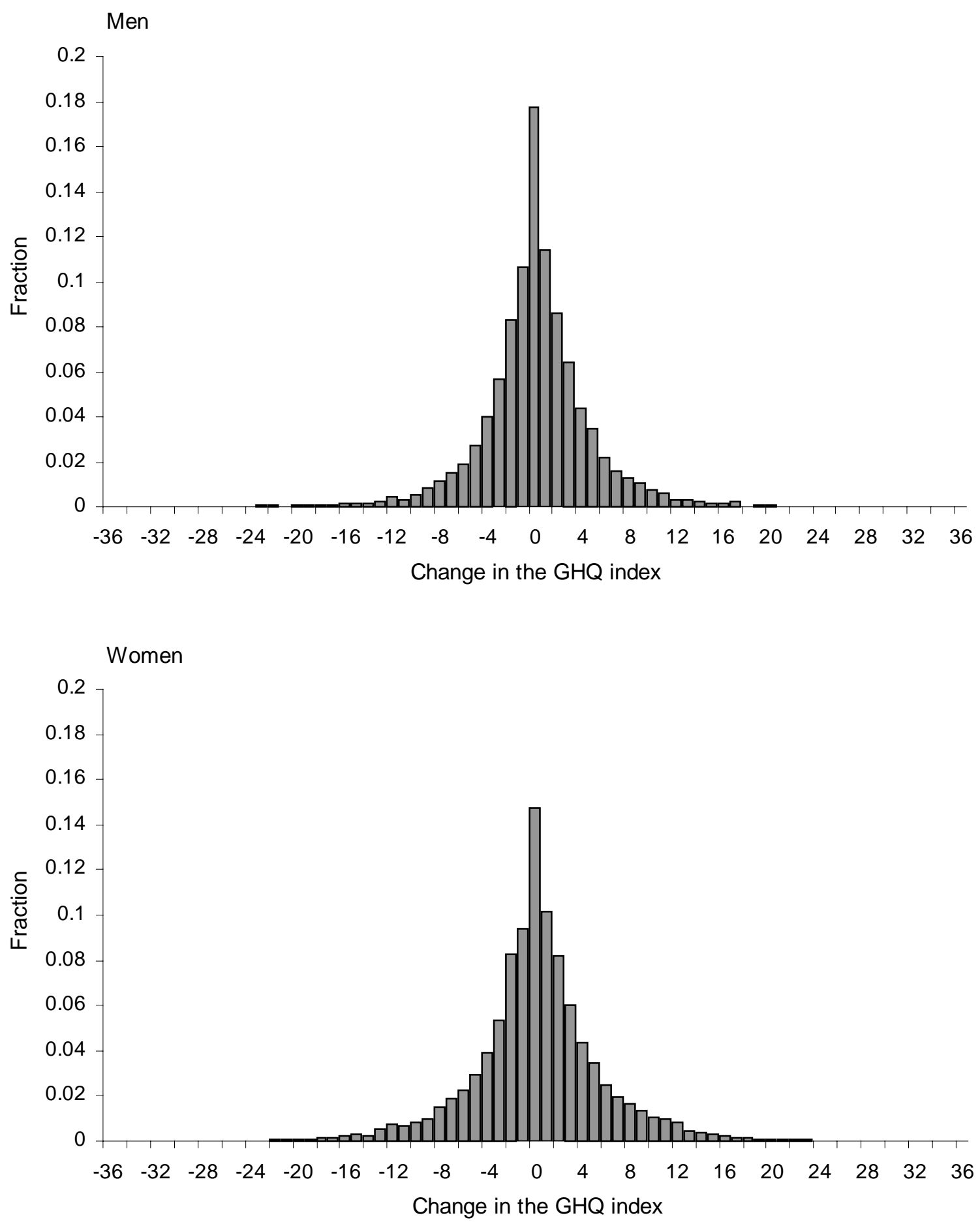

Figure 2: The distribution of changes in mental health (GHQ index) observed between waves $t-1$ and $t$ by gender 
Table 1

Mental health (GHQ index) by type of employment and the distribution of types of employment by gender

\begin{tabular}{|c|c|c|c|c|c|c|}
\hline & \multicolumn{3}{|c|}{ Men $(\mathrm{N}=11,166)$} & \multicolumn{3}{|c|}{ Women $(\mathrm{N}=12,808)$} \\
\hline & Mean & S.D. & $\begin{array}{c}\% \text { of } \\
\text { workers }\end{array}$ & Mean & S.D. & $\begin{array}{c}\% \text { of } \\
\text { workers }\end{array}$ \\
\hline All types of employment & 10.037 & 4.640 & 100.0 & 11.383 & 5.139 & 100.0 \\
\hline \multicolumn{7}{|l|}{ Contract type: } \\
\hline Permanent contract & 10.060 & 4.612 & 93.3 & 11.380 & 5.113 & 90.5 \\
\hline Seasonal/casual contract & 10.090 & 5.297 & 3.8 & 11.400 & 5.287 & 6.2 \\
\hline Fixed term contract & 9.229 & 4.586 & 2.9 & 11.425 & 5.569 & 3.3 \\
\hline \multicolumn{7}{|l|}{ Place of work: } \\
\hline Employer's premises & 10.056 & 4.685 & 78.5 & 11.400 & 5.144 & 92.3 \\
\hline Working at home & 11.471 & 4.966 & 0.8 & 10.662 & 5.095 & 1.1 \\
\hline Driving/travelling & 9.933 & 4.390 & 12.3 & 11.220 & 5.191 & 2.8 \\
\hline More than one place & 9.879 & 4.522 & 8.4 & 11.314 & 4.992 & 3.8 \\
\hline \multicolumn{7}{|l|}{ Times of work: } \\
\hline During the day & 10.145 & 4.709 & 73.5 & 11.361 & 5.147 & 66.5 \\
\hline Mornings only & 10.128 & 4.488 & 1.6 & 11.740 & 5.168 & 9.0 \\
\hline Other parts of the day & 9.715 & 4.219 & 3.9 & 11.565 & 5.270 & 10.3 \\
\hline Rotating shifts & 9.385 & 4.181 & 12.9 & 11.122 & 4.931 & 6.4 \\
\hline Varying patterns & 10.236 & 4.846 & 8.1 & 11.138 & 5.014 & 7.8 \\
\hline \multicolumn{7}{|l|}{ Hours of work: } \\
\hline Long hours (>48 per week) & 9.917 & 4.606 & 28.8 & 11.582 & 5.390 & 7.1 \\
\hline Normal hours (30-48 per week) & 10.102 & 4.642 & 66.7 & 11.190 & 5.070 & 55.0 \\
\hline Medium hours (16-29 per week) & 10.083 & 5.100 & 1.8 & 11.702 & 5.195 & 22.9 \\
\hline Short hours (1-15 per week) & 9.660 & 4.618 & 2.7 & 11.515 & 5.156 & 15.0 \\
\hline
\end{tabular}

Notes: 'Other parts of the day' include afternoons only, evenings only, nights only, lunch and evening, and other patterns. $\mathrm{N}$ is number of person-wave observations. 
Table 2

Changes in the GHQ index between waves $t$ - 1 and $t$

\begin{tabular}{|c|c|c|c|c|c|c|}
\hline \multirow[b]{2}{*}{ Change } & \multicolumn{3}{|c|}{ Men } & \multicolumn{3}{|c|}{ Women } \\
\hline & Freq. & $\%$ & Cum. $\%$ & Freq. & $\%$ & Cum. \% \\
\hline$<-6$ & 523 & 5.9 & 5.9 & 863 & 8.7 & 8.7 \\
\hline-6 & 168 & 1.9 & 7.8 & 223 & 2.2 & 10.9 \\
\hline-5 & 239 & 2.7 & 10.5 & 291 & 2.9 & 13.8 \\
\hline-4 & 354 & 4.0 & 14.5 & 387 & 3.9 & 17.7 \\
\hline-3 & 506 & 5.7 & 20.2 & 530 & 5.3 & 23.0 \\
\hline-2 & 737 & 8.3 & 28.5 & 823 & 8.3 & 31.3 \\
\hline-1 & 946 & 10.6 & 39.1 & 937 & 9.4 & 40.7 \\
\hline 0 & 1580 & 17.7 & 56.8 & 1468 & 14.7 & 55.4 \\
\hline 1 & 1013 & 11.4 & 68.2 & 1015 & 10.2 & 65.6 \\
\hline 2 & 766 & 8.6 & 76.8 & 820 & 8.2 & 73.8 \\
\hline 3 & 572 & 6.4 & 83.2 & 600 & 6.0 & 79.8 \\
\hline 4 & 392 & 4.4 & 87.6 & 437 & 4.4 & 84.2 \\
\hline 5 & 311 & 3.5 & 91.1 & 344 & 3.4 & 87.6 \\
\hline 6 & 198 & 2.2 & 93.3 & 248 & 2.5 & 90.1 \\
\hline$>6$ & 604 & 6.7 & 100.0 & 984 & 9.9 & 100.0 \\
\hline All & 8909 & 100.00 & & 9970 & 100.00 & \\
\hline
\end{tabular}

Note: 'Change' indicates an increase $(1,2, \ldots)$, a decrease $(-1,-2, \ldots)$, and no variation $(0)$ in the GHQ index between waves $t-1$ and $t(t=1992, \ldots, 1997)$. 
Table 3

The effect of non-standard contracts on the GHQ index

\begin{tabular}{|c|c|c|c|c|c|c|}
\hline & \multicolumn{2}{|c|}{ OLS } & \multicolumn{2}{|l|}{$\mathrm{FE}$} & \multicolumn{2}{|c|}{$\mathrm{FE}(-2)$} \\
\hline & Coeff. & S.E. & Coeff. & S.E. & Coeff. & S.E. \\
\hline \multicolumn{7}{|l|}{ Men } \\
\hline Seasonal/casual (SC) & $0.545 *$ & $(0.318)$ & & & & \\
\hline Fixed term $(\mathrm{FX})$ & $-0.695 * *$ & $(0.299)$ & & & & \\
\hline Entry into SC & & & 0.728 & $(0.483)$ & $1.462 * *$ & $(0.641)$ \\
\hline Exit from SC & & & $-1.215 * * *$ & $(0.385)$ & -0.396 & $(0.504)$ \\
\hline Stay in SC & & & -0.218 & $(0.445)$ & 0.756 & $(0.564)$ \\
\hline Entry into FX & & & -0.011 & $(0.426)$ & 0.144 & $(0.562)$ \\
\hline Exit from FX & & & 0.392 & $(0.388)$ & -0.256 & $(0.541)$ \\
\hline Stay in FX & & & 0.428 & $(0.495)$ & -0.717 & $(0.641)$ \\
\hline $\mathrm{N}$ & \multicolumn{2}{|c|}{11166} & \multicolumn{2}{|c|}{8909} & \multicolumn{2}{|c|}{5537} \\
\hline $\mathrm{R}^{2}$ & \multicolumn{2}{|c|}{0.0403} & \multicolumn{2}{|c|}{0.0149} & \multicolumn{2}{|c|}{0.0123} \\
\hline \multicolumn{7}{|l|}{ Women } \\
\hline Seasonal/casual (SC) & 0.125 & $(0.218)$ & & & & \\
\hline Fixed term $(\mathrm{FX})$ & 0.039 & $(0.344)$ & & & & \\
\hline Entry into SC & & & -0.223 & $(0.375)$ & -0.106 & $(0.497)$ \\
\hline Exit from SC & & & -0.052 & $(0.318)$ & $0.747 *$ & $(0.426)$ \\
\hline Stay in SC & & & 0.090 & $(0.409)$ & $-0.896 *$ & $(0.540)$ \\
\hline Entry into FX & & & -0.070 & $(0.464)$ & -1.038 & $(0.638)$ \\
\hline Exit from FX & & & -0.319 & $(0.412)$ & -0.480 & $(0.556)$ \\
\hline Stay in FX & & & 0.508 & $(0.487)$ & -0.001 & $(0.660)$ \\
\hline $\mathrm{N}$ & \multicolumn{2}{|c|}{12808} & \multicolumn{2}{|c|}{9970} & \multicolumn{2}{|c|}{6291} \\
\hline $\mathrm{R}^{2}$ & \multicolumn{2}{|c|}{0.0338} & \multicolumn{2}{|c|}{0.0095} & \multicolumn{2}{|c|}{0.0083} \\
\hline
\end{tabular}

Notes: The base category in the OLS regressions is 'permanent contract'. FE: model estimated on first differences, that is changes between $\mathrm{t}-1$ and $\mathrm{t}$. FE(-2): model estimated on two-period lagged first differences, that is changes between $\mathrm{t}-3$ and $\mathrm{t}-2$. Other variables included in OLS are: number of cigarettes smoked, age group (4 categories), education (6), cohort of entry in the labour market (4), marital status (3), number of children in 5 different age groups, years of full-time experience, years of part-time experience, housing tenure (3), industry (10), occupation (9), sector (5), firm size (8), unemployment/vacancy ratio, union coverage (2), and region (7). Other variables included in FE and FE(-2) are first differences and two-period lagged first differences in number of cigarettes, marital status, number of children in 5 different age groups, years of full-time experience, years of part-time experience, housing tenure, industry, occupation, sector, firm size, unemployment/vacancy ratio, union coverage, and region. $\mathrm{N}$ denotes the number of person-wave observations for OLS regressions, the number of first differences and the number of two-period lagged first differences in person-wave observations for FE and FE(-2).

$* \mathrm{p}<0.10, * * \mathrm{p}<0.05, * * * \mathrm{p}<0.01$. 
Table 4

The effect of non-standard places of work on the GHQ index

\begin{tabular}{|c|c|c|c|c|c|c|}
\hline & \multicolumn{2}{|c|}{ OLS } & \multicolumn{2}{|c|}{$\mathrm{FE}$} & \multicolumn{2}{|c|}{$\mathrm{FE}(-2)$} \\
\hline & Coeff. & S.E. & Coeff. & S.E. & Coeff. & S.E. \\
\hline \multicolumn{7}{|l|}{ Men } \\
\hline At home (AH) & 0.825 & $(0.720)$ & & & & \\
\hline Driving/travelling (DR) & -0.020 & $(0.203)$ & & & & \\
\hline More than one place (M1) & -0.094 & $(0.206)$ & & & & \\
\hline Entry into $\mathrm{AH}$ & & & $1.406 *$ & $(0.753)$ & -1.117 & $(0.991)$ \\
\hline Exit from $\mathrm{AH}$ & & & -0.158 & $(0.805)$ & 1.140 & (1.147) \\
\hline Stay in AH & & & 0.887 & $(0.798)$ & 0.797 & (1.074) \\
\hline Entry into DR & & & -0.244 & $(0.265)$ & -0.054 & $(0.336)$ \\
\hline Exit from DR & & & $-0.485 *$ & $(0.255)$ & $0.618 *$ & $(0.336)$ \\
\hline Stay in DR & & & 0.033 & $(0.177)$ & -0.307 & $(0.226)$ \\
\hline Entry into M1 & & & 0.124 & $(0.252)$ & $-0.670 * *$ & $(0.325)$ \\
\hline Exit from M1 & & & 0.385 & $(0.256)$ & -0.064 & $(0.319)$ \\
\hline Stay in M1 & & & 0.247 & $(0.248)$ & 0.059 & $(0.326)$ \\
\hline $\mathrm{N}$ & \multicolumn{2}{|c|}{11166} & \multicolumn{2}{|c|}{8909} & \multicolumn{2}{|c|}{5537} \\
\hline $\mathrm{R}^{2}$ & \multicolumn{2}{|c|}{0.0394} & \multicolumn{2}{|c|}{0.0145} & \multicolumn{2}{|c|}{0.0125} \\
\hline
\end{tabular}

\section{Women}

$\begin{array}{lll}\text { At home (AH) } & -0.496 & (0.620) \\ \text { Driving/travelling (DR) } & -0.372 & (0.346) \\ \text { More than one place (M1) } & -0.191 & (0.283)\end{array}$

\begin{tabular}{|c|c|c|c|c|c|}
\hline \multicolumn{2}{|l|}{ Entry into $\mathrm{AH}$} & 0.170 & (1.061) & 1.391 & (1.461) \\
\hline \multicolumn{2}{|l|}{ Exit from AH } & 0.625 & $(0.944)$ & 0.124 & (1.278) \\
\hline \multicolumn{2}{|l|}{ Stay in AH } & -0.229 & $(0.658)$ & 0.034 & $(0.890)$ \\
\hline \multicolumn{2}{|l|}{ Entry into DR } & -0.027 & $(0.491)$ & -0.554 & $(0.639)$ \\
\hline \multicolumn{2}{|l|}{ Exit from DR } & 0.600 & $(0.513)$ & -0.261 & (0.694) \\
\hline \multicolumn{2}{|l|}{ Stay in DR } & $0.873 *$ & $(0.458)$ & -0.244 & $(0.627)$ \\
\hline \multicolumn{2}{|l|}{ Entry into M1 } & $-0.907 * *$ & $(0.400)$ & -0.248 & $(0.538)$ \\
\hline \multicolumn{2}{|l|}{ Exit from M1 } & -0.320 & $(0.400)$ & $1.001 *$ & $(0.536)$ \\
\hline \multicolumn{2}{|l|}{ Stay in M1 } & -0.104 & $(0.424)$ & 0.113 & $(0.574)$ \\
\hline $\mathrm{N}$ & 12808 & \multicolumn{2}{|c|}{9970} & \multicolumn{2}{|c|}{6291} \\
\hline $\mathrm{R}^{2}$ & 0.0341 & \multicolumn{2}{|c|}{0.0103} & \multicolumn{2}{|c|}{0.0079} \\
\hline
\end{tabular}

Notes: The base category in the OLS regressions is 'employer's premises'. For definitions and variables included in the regressions, see notes of Table 3 .

$* \mathrm{p}<0.10, * * \mathrm{p}<0.05, * * * \mathrm{p}<0.01$. 
Table 5

The effect of non-standard times of work on the GHQ index

\begin{tabular}{|c|c|c|c|c|c|c|}
\hline & \multicolumn{2}{|l|}{ OLS } & \multicolumn{2}{|l|}{ FE } & \multicolumn{2}{|c|}{$\mathrm{FE}(-2)$} \\
\hline & Coeff. & S.E. & Coeff. & S.E. & Coeff. & S.E. \\
\hline \multicolumn{7}{|l|}{ Men } \\
\hline Mornings only (MO) & 0.016 & $(0.470)$ & & & & \\
\hline Other parts of the day (OD) & -0.209 & $(0.305)$ & & & & \\
\hline Rotating shifts (RS) & $-0.670 * * *$ & $(0.212)$ & & & & \\
\hline Varying patterns (VP) & 0.034 & $(0.241)$ & & & & \\
\hline Entry into MO & & & 0.811 & $(0.751)$ & $-2.441 * *$ & $(1.115)$ \\
\hline Exit from MO & & & $-1.118 *$ & $(0.671)$ & -0.036 & $(0.884)$ \\
\hline Stay in MO & & & -0.118 & $(0.512)$ & 0.237 & $(0.679)$ \\
\hline Entry into OD & & & -0.622 & $(0.464)$ & -0.546 & $(0.624)$ \\
\hline Exit from OD & & & -0.341 & $(0.407)$ & -0.094 & $(0.577)$ \\
\hline Stay in OD & & & 0.111 & $(0.341)$ & 0.122 & $(0.426)$ \\
\hline Entry into RS & & & -0.417 & $(0.342)$ & 0.018 & $(0.461)$ \\
\hline Exit from RS & & & -0.411 & $(0.329)$ & -0.094 & $(0.466)$ \\
\hline Stay in RS & & & -0.095 & $(0.157)$ & 0.080 & $(0.198)$ \\
\hline Entry into VP & & & -0.345 & $(0.285)$ & 0.282 & $(0.497)$ \\
\hline Exit from VP & & & -0.108 & $(0.303)$ & 0.309 & $(0.427)$ \\
\hline Stay in VP & & & -0.080 & $(0.229)$ & 0.200 & $(0.292)$ \\
\hline $\mathrm{N}$ & \multirow{2}{*}{\multicolumn{2}{|c|}{11166}} & \multicolumn{2}{|c|}{8909} & \multicolumn{2}{|c|}{5537} \\
\hline $\mathrm{R}^{2}$ & & & \multicolumn{2}{|c|}{0.0146} & \multicolumn{2}{|c|}{0.0120} \\
\hline \multicolumn{7}{|l|}{ Women } \\
\hline Mornings only (MO) & 0.032 & $(0.238)$ & & & & \\
\hline Other parts of the day (OD) & 0.042 & $(0.226)$ & & & & \\
\hline Rotating shifts (RS) & -0.266 & $(0.254)$ & & & & \\
\hline Varying patterns (VP) & $-0.415 *$ & $(0.223)$ & & & & \\
\hline Entry into MO & & & -0.551 & $(0.402)$ & $-1.184 * *$ & $(0.568)$ \\
\hline Exit from MO & & & $-1.120 * * *$ & $(0.386)$ & 0.819 & $(0.556)$ \\
\hline Stay in MO & & & -0.120 & $(0.242)$ & -0.089 & $(0.318)$ \\
\hline Entry into OD & & & -0.667 & $(0.421)$ & -0.532 & $(0.571)$ \\
\hline Exit from OD & & & -0.171 & $(0.338)$ & 0.520 & $(0.475)$ \\
\hline Stay in OD & & & 0.174 & $(0.227)$ & 0.042 & $(0.289)$ \\
\hline Entry into RS & & & -0.343 & $(0.459)$ & 0.558 & $(0.652)$ \\
\hline Exit from RS & & & -0.216 & $(0.426)$ & -0.259 & $(0.653)$ \\
\hline Stay in RS & & & $0.441 *$ & $(0.259)$ & 0.107 & $(0.331)$ \\
\hline Entry into VP & & & -0.346 & $(0.333)$ & -0.064 & $(0.601)$ \\
\hline Exit from VP & & & $0.882 * * *$ & $(0.335)$ & 0.673 & $(0.472)$ \\
\hline Stay in VP & & & 0.347 & $(0.270)$ & 0.021 & $(0.343)$ \\
\hline $\mathrm{N}$ & \multirow{2}{*}{\multicolumn{2}{|c|}{$\begin{array}{c}12808 \\
0.0344\end{array}$}} & \multicolumn{2}{|c|}{9970} & \multicolumn{2}{|c|}{6291} \\
\hline $\mathrm{R}^{2}$ & & & \multicolumn{2}{|c|}{0.0122} & \multicolumn{2}{|c|}{0.0088} \\
\hline
\end{tabular}

Notes: The base category in the OLS regressions is 'during the day'. For definitions and variables included in the regressions, see notes of Table 3 .

$* \mathrm{p}<0.10, * * \mathrm{p}<0.05, * * * \mathrm{p}<0.01$. 
Table 6

The effect of non-standard hours of work on the GHQ index

\begin{tabular}{|c|c|c|c|c|c|c|}
\hline & \multicolumn{2}{|c|}{ OLS } & \multicolumn{2}{|c|}{$\mathrm{FE}$} & \multicolumn{2}{|c|}{$\mathrm{FE}(-2)$} \\
\hline & Coeff. & S.E. & Coeff. & S.E. & Coeff. & S.E. \\
\hline \multicolumn{7}{|l|}{ Men } \\
\hline Long hours (LH) & -0.224 & $(0.146)$ & & & & \\
\hline Medium hours (MH) & 0.155 & $(0.414)$ & & & & \\
\hline Short hours (SH) & 0.316 & $(0.389)$ & & & & \\
\hline Entry into LH & & & -0.138 & $(0.176)$ & -0.221 & $(0.227)$ \\
\hline Exit from LH & & & 0.135 & $(0.180)$ & 0.203 & $(0.232)$ \\
\hline Stay in LH & & & -0.180 & $(0.123)$ & 0.120 & $(0.162)$ \\
\hline Entry into $\mathrm{MH}$ & & & -0.319 & $(0.635)$ & -0.356 & $(0.773)$ \\
\hline Exit from $\mathrm{MH}$ & & & -0.016 & $(0.531)$ & -0.188 & $(0.777)$ \\
\hline Stay in $\mathrm{MH}$ & & & 0.697 & $(0.647)$ & 0.084 & $(0.891)$ \\
\hline Entry into SH & & & 0.179 & $(0.804)$ & 0.620 & (1.288) \\
\hline Exit from $\mathrm{SH}$ & & & $-0.915 *$ & $(0.513)$ & -0.892 & $(0.641)$ \\
\hline Stay in SH & & & 0.925 * & $(0.486)$ & $1.161 * *$ & $(0.567)$ \\
\hline $\mathrm{N}$ & \multicolumn{2}{|c|}{11166} & \multicolumn{2}{|c|}{8909} & \multicolumn{2}{|c|}{5537} \\
\hline $\mathrm{R}^{2}$ & \multicolumn{2}{|c|}{0.0398} & \multicolumn{2}{|c|}{0.0146} & \multicolumn{2}{|c|}{0.0126} \\
\hline \multicolumn{7}{|l|}{ Women } \\
\hline Long hours (LH) & 0.191 & $(0.248)$ & & & & \\
\hline Medium hours (MH) & 0.171 & $(0.177)$ & & & & \\
\hline Short hours (SH) & 0.072 & $(0.209)$ & & & & \\
\hline Entry into LH & & & 0.085 & $(0.309)$ & 0.325 & $(0.401)$ \\
\hline Exit from LH & & & 0.026 & $(0.323)$ & $-0.801 *$ & $(0.448)$ \\
\hline Stay in LH & & & 0.414 & $(0.276)$ & 0.396 & $(0.383)$ \\
\hline Entry into $\mathrm{MH}$ & & & 0.255 & $(0.308)$ & -0.026 & $(0.403)$ \\
\hline Exit from $\mathrm{MH}$ & & & -0.215 & $(0.279)$ & -0.029 & $(0.382)$ \\
\hline Stay in $\mathrm{MH}$ & & & 0.011 & $(0.237)$ & -0.015 & $(0.311)$ \\
\hline Entry into SH & & & 0.569 & $(0.404)$ & 0.181 & $(0.523)$ \\
\hline Exit from $\mathrm{SH}$ & & & -0.330 & $(0.330)$ & 0.415 & $(0.451)$ \\
\hline Stay in SH & & & 0.059 & $(0.243)$ & 0.120 & (0.309) \\
\hline $\mathrm{N}$ & \multicolumn{2}{|c|}{12808} & \multicolumn{2}{|c|}{9970} & \multicolumn{2}{|c|}{6291} \\
\hline $\mathrm{R}^{2}$ & \multicolumn{2}{|c|}{0.0340} & \multicolumn{2}{|c|}{0.0099} & \multicolumn{2}{|c|}{0.0080} \\
\hline
\end{tabular}

Notes: The base category in the OLS regressions is 'normal hours' (30-48 per week). For definitions and variables included in the regressions, see notes of Table 3.

$* \mathrm{p}<0.10, * * \mathrm{p}<0.05, * * * \mathrm{p}<0.01$. 
Table 7

Relationship between health endowment and employment-related inputs - Probit estimates

\begin{tabular}{|c|c|c|c|c|c|c|c|c|}
\hline \multirow[b]{3}{*}{$\begin{array}{l}\text { Dependent } \\
\text { variable }\end{array}$} & \multicolumn{4}{|c|}{ Men } & \multicolumn{4}{|c|}{ Women } \\
\hline & \multicolumn{2}{|c|}{$\mathrm{FE}$} & \multicolumn{2}{|c|}{$\mathrm{FE}(-2)$} & \multicolumn{2}{|c|}{$\mathrm{FE}$} & \multicolumn{2}{|c|}{$\mathrm{FE}(-2)$} \\
\hline & $\begin{array}{c}\text { Marginal } \\
\text { effect }\end{array}$ & S.E. & $\begin{array}{c}\text { Marginal } \\
\text { effect }\end{array}$ & S.E. & $\begin{array}{c}\text { Marginal } \\
\text { effect }\end{array}$ & S.E. & $\begin{array}{c}\text { Marginal } \\
\text { effect }\end{array}$ & S.E. \\
\hline Entry into SC & -0.085 & $(2.296)$ & -0.019 & $(2.837)$ & -0.164 & $(2.613)$ & -0.053 & $(3.152)$ \\
\hline Exit from SC & -0.139 & $(2.922)$ & -0.034 & (3.784) & -0.250 & $(3.210)$ & -0.078 & (3.812) \\
\hline Stay in SC & -0.102 & $(2.508)$ & -0.024 & (3.211) & -0.146 & $(2.471)$ & -0.044 & $(2.870)$ \\
\hline Entry into FX & -0.121 & $(2.733)$ & -0.026 & $(3.342)$ & -0.115 & $(2.192)$ & -0.033 & $(2.508)$ \\
\hline Exit from FX & -0.139 & $(2.917)$ & -0.027 & $(3.410)$ & -0.143 & $(2.444)$ & -0.044 & (2.878) \\
\hline Stay in FX & -0.082 & (2.257) & -0.019 & (2.873) & -0.094 & (1.986) & -0.029 & (2.337) \\
\hline Entry into $\mathrm{AH}$ & -0.033 & $(1.530)$ & -0.018 & $(1.784)$ & -0.022 & $(0.968)$ & -0.002 & (1.126) \\
\hline Exit from $\mathrm{AH}$ & -0.025 & $(1.343)$ & -0.012 & (1.479) & -0.026 & (1.069) & -0.002 & $(1.286)$ \\
\hline Stay in $\mathrm{AH}$ & -0.028 & $(1.415)$ & -0.016 & (1.698) & -0.054 & $(1.524)$ & -0.004 & (1.782) \\
\hline Entry into DR & -0.300 & $(4.544)$ & -0.208 & $(5.958)$ & -0.108 & $(2.155)$ & -0.008 & $(2.579)$ \\
\hline Exit from DR & -0.327 & (4.738) & -0.198 & $(5.813)$ & -0.103 & $(2.108)$ & -0.008 & $(2.464)$ \\
\hline Stay in DR & -0.642 & $(6.501)$ & -0.415 & $(8.225)$ & -0.110 & $(2.181)$ & -0.008 & $(2.561)$ \\
\hline Entry into M1 & -0.323 & $(4.708)$ & -0.209 & $(5.960)$ & -0.171 & $(2.704)$ & -0.013 & (3.223) \\
\hline Exit from M1 & -0.312 & $(4.630)$ & -0.227 & $(6.206)$ & -0.168 & $(2.683)$ & -0.012 & (3.060) \\
\hline Stay in M1 & -0.310 & $(4.625)$ & -0.178 & $(5.520)$ & -0.135 & $(2.408)$ & -0.010 & $(2.812)$ \\
\hline Entry into $\mathrm{MO}$ & -0.044 & $(1.526)$ & -0.018 & $(1.678)$ & -0.178 & $(2.582)$ & 0.005 & (2.914) \\
\hline Exit from MO & -0.051 & (1.649) & -0.029 & $(2.135)$ & -0.186 & $(2.640)$ & 0.005 & $(2.960)$ \\
\hline Stay in MO & -0.095 & $(2.246)$ & -0.048 & $(2.758)$ & -0.594 & $(4.607)$ & 0.018 & (5.639) \\
\hline Entry into OD & -0.120 & $(2.516)$ & -0.055 & $(2.941)$ & -0.160 & $(2.454)$ & 0.004 & (2.798) \\
\hline Exit from OD & -0.150 & $(2.815)$ & -0.061 & (3.119) & -0.256 & $(3.079)$ & 0.006 & (3.430) \\
\hline Stay in OD & -0.219 & (3.387) & -0.121 & $(4.363)$ & -0.655 & $(4.817)$ & 0.022 & (6.130) \\
\hline Entry into RS & -0.221 & $(3.404)$ & -0.111 & $(4.172)$ & -0.135 & $(2.253)$ & 0.003 & $(2.520)$ \\
\hline Exit from RS & -0.251 & (3.619) & -0.109 & (4.140) & -0.163 & $(2.471)$ & 0.003 & $(2.532)$ \\
\hline Stay in RS & -1.155 & (7.414) & -0.636 & $(9.496)$ & -0.435 & $(3.981)$ & 0.014 & $(4.935)$ \\
\hline Entry into VP & -0.322 & (4.082) & -0.094 & $(3.857)$ & -0.268 & $(3.154)$ & 0.004 & $(2.778)$ \\
\hline Exit from VP & -0.286 & (3.859) & -0.130 & (4.514) & -0.259 & $(3.097)$ & 0.006 & (3.451) \\
\hline Stay in VP & -0.485 & $(4.970)$ & -0.251 & (6.190) & -0.405 & $(3.845)$ & 0.013 & $(4.805)$ \\
\hline Entry into LH & -0.488 & $(6.592)$ & -0.175 & $(8.138)$ & -0.220 & $(3.300)$ & 0.030 & $(4.032)$ \\
\hline Exit from LH & -0.456 & $(6.385)$ & -0.171 & $(8.046)$ & -0.204 & $(3.179)$ & 0.024 & (3.616) \\
\hline Stay in LH & -1.167 & $(9.489)$ & -0.407 & (11.611) & -0.274 & $(3.659)$ & 0.033 & $(4.201)$ \\
\hline Entry into $\mathrm{MH}$ & -0.044 & (2.064) & -0.018 & $(2.713)$ & -0.409 & $(4.428)$ & 0.054 & $(5.336)$ \\
\hline Exit from MH & -0.047 & $(2.123)$ & -0.013 & $(2.323)$ & -0.362 & (4.180) & 0.047 & (5.013) \\
\hline Stay in $\mathrm{MH}$ & -0.039 & $(1.938)$ & -0.013 & $(2.306)$ & -1.139 & $(6.952)$ & 0.144 & $(8.232)$ \\
\hline Entry into SH & -0.023 & (1.483) & -0.005 & $(1.435)$ & -0.165 & $(2.865)$ & 0.022 & (3.494) \\
\hline Exit from SH & -0.056 & $(2.327)$ & -0.023 & $(3.067)$ & -0.282 & $(3.715)$ & 0.038 & (4.520) \\
\hline Stay in $\mathrm{SH}$ & -0.058 & (2.371) & -0.025 & (3.212) & -0.657 & $(5.502)$ & 0.092 & $(6.806)$ \\
\hline $\mathrm{N}$ & \multicolumn{2}{|c|}{8909} & \multicolumn{2}{|c|}{5537} & \multicolumn{2}{|c|}{9970} & \multicolumn{2}{|c|}{6291} \\
\hline
\end{tabular}

Notes: Obtained from 36 probit regressions, one for each of the employment-related inputs in $\mathrm{C}$ (dependent variable). The only explanatory variable are the $\mathrm{FE}$ or $\mathrm{FE}(-2)$ residuals obtained from equation (5) or equation (8). Figures are marginal effects $(\mathrm{dF} / \mathrm{dx})$ evaluated at the sample means. Both marginal effect and standard errors have been multiplied by $10^{4}$. 
Table 8

Sample sizes and means of the GHQ index by age, education, and gender

\begin{tabular}{|c|c|c|c|c|c|c|c|}
\hline & & \multicolumn{3}{|c|}{ Men } & \multicolumn{3}{|c|}{ Women } \\
\hline & & $\mathrm{N}$ & Mean of GHQ & S.D. & $\mathrm{N}$ & Mean of GHQ & S.D. \\
\hline \multicolumn{8}{|l|}{ Age groups: } \\
\hline$<30$ & [A1] & 4544 & 9.423 & 0.066 & 5013 & 10.963 & 0.073 \\
\hline $30-44$ & [A2] & 4769 & 10.374 & 0.069 & 5253 & 11.701 & 0.071 \\
\hline $45-60$ & [A3] & 1853 & 10.676 & 0.108 & 2542 & 11.554 & 0.100 \\
\hline \multicolumn{8}{|c|}{ Education levels: } \\
\hline$<$ O-level & [E1] & 2782 & 9.896 & 0.086 & 3867 & 11.743 & 0.083 \\
\hline O-level & [E2] & 2796 & 9.744 & 0.084 & 4136 & 11.071 & 0.078 \\
\hline A-level & [E3] & 1805 & 10.097 & 0.112 & 1415 & 11.034 & 0.139 \\
\hline$>$ A-level & [E4] & 3783 & 10.328 & 0.078 & 3390 & 11.500 & 0.089 \\
\hline
\end{tabular}

Group differences ( |t-test $\mid)$ :

$\begin{array}{lcc}{[\mathrm{A} 1]-[\mathrm{A} 2]} & -9.952 * * * & -7.256 * * * \\ {[\mathrm{~A} 1]-[\mathrm{A} 3]} & -10.074 * * * & -4.732 * * * \\ {[\mathrm{~A} 2]-[\mathrm{A} 3]} & -2.340 * * * & 1.194 \\ & & 5.903 * * * \\ {[\mathrm{E} 1]-[\mathrm{E} 2]} & 1.265 & 4.386 * * * \\ {[\mathrm{E} 1]-[\mathrm{E} 3]} & -1.431 & 1.990 * * \\ {[\mathrm{E} 1]-[\mathrm{E} 4]} & -3.687 * * * & 0.240 \\ {[\mathrm{E} 2]-[\mathrm{E} 3]} & -2.564 * * & -3.639 * * * \\ {[\mathrm{E} 2]-[\mathrm{E} 4]} & -5.053 * * * & -2.825 * * * \\ {[\mathrm{E} 3]-[\mathrm{E} 4]} & -1.695 * & \end{array}$

Notes: $\mathrm{N}$ is number of person-wave observations. The t-test is for the null hypothesis that the means are equal $v s$ the alternative that they are different.

$* \mathrm{p}<0.10-* * \mathrm{p}<0.05-* * * \mathrm{p}<0.01$. 


\section{Appendix}

Table A.1

Summary statistics

\begin{tabular}{|c|c|c|c|c|}
\hline & \multicolumn{2}{|c|}{$\operatorname{Men}(N=11166)$} & \multicolumn{2}{|c|}{ Women $(\mathrm{N}=12808)$} \\
\hline & Mean & S.D. & Mean & S.D. \\
\hline Number of cigarettes smoked (per day) & 4.304 & 8.430 & 4.272 & 7.810 \\
\hline $\begin{array}{l}\text { Age group: } \\
\qquad \begin{array}{l}16-25 \\
26-35 \\
36-45 \\
46-60 \text { (base) }\end{array}\end{array}$ & $\begin{array}{l}0.248 \\
0.326 \\
0.260 \\
0.166\end{array}$ & & $\begin{array}{l}0.233 \\
0.301 \\
0.267 \\
0.198\end{array}$ & \\
\hline $\begin{array}{l}\text { Education: } \\
\text { No qualifications } \\
\text { Less than O level/GCSE } \\
\text { O level/GCSE } \\
\text { A level } \\
\text { Higher vocational degree } \\
\text { University degree or more }\end{array}$ & $\begin{array}{l}0.139 \\
0.084 \\
0.211 \\
0.162 \\
0.258 \\
0.145\end{array}$ & & $\begin{array}{l}0.167 \\
0.108 \\
0.282 \\
0.118 \\
0.213 \\
0.113\end{array}$ & \\
\hline $\begin{array}{l}\text { Marital status: } \\
\text { Separated, divorced or widow } \\
\text { Never married } \\
\text { Married, or living with partner (base) }\end{array}$ & $\begin{array}{l}0.049 \\
0.270 \\
0.681\end{array}$ & & $\begin{array}{l}0.099 \\
0.198 \\
0.704\end{array}$ & \\
\hline $\begin{array}{l}\text { Number of children aged: } \\
0-2 \\
2-4 \\
5-11 \\
12-15 \\
16-18\end{array}$ & $\begin{array}{l}0.090 \\
0.097 \\
0.301 \\
0.177 \\
0.043\end{array}$ & $\begin{array}{l}0.295 \\
0.307 \\
0.642 \\
0.451 \\
0.211\end{array}$ & $\begin{array}{l}0.061 \\
0.071 \\
0.312 \\
0.209 \\
0.042\end{array}$ & $\begin{array}{l}0.242 \\
0.262 \\
0.648 \\
0.484 \\
0.210\end{array}$ \\
\hline $\begin{array}{l}\text { Full-time experience (years) } \\
\text { Part-time experience (years) }\end{array}$ & $\begin{array}{r}17.110 \\
0.236\end{array}$ & $\begin{array}{r}10.886 \\
1.155\end{array}$ & $\begin{array}{r}10.188 \\
4.740\end{array}$ & $\begin{array}{l}7.443 \\
6.170\end{array}$ \\
\hline $\begin{array}{l}\text { Housing tenure: } \\
\text { Social housing } \\
\text { Rented accommodation } \\
\text { Owner (base) }\end{array}$ & $\begin{array}{l}0.099 \\
0.083 \\
0.818\end{array}$ & & $\begin{array}{l}0.125 \\
0.077 \\
0.797\end{array}$ & \\
\hline $\begin{array}{l}\text { Industry: } \\
\text { Agriculture (base) } \\
\text { Energy } \\
\text { Extraction } \\
\text { Metal } \\
\text { Other manufacturing } \\
\text { Construction } \\
\text { Distribution and trade } \\
\text { Transport } \\
\text { Banking } \\
\text { Other services }\end{array}$ & $\begin{array}{l}0.028 \\
0.037 \\
0.052 \\
0.144 \\
0.125 \\
0.047 \\
0.157 \\
0.081 \\
0.120 \\
0.209\end{array}$ & & $\begin{array}{l}0.017 \\
0.007 \\
0.019 \\
0.042 \\
0.070 \\
0.005 \\
0.234 \\
0.031 \\
0.126 \\
0.447\end{array}$ & \\
\hline
\end{tabular}


(Table A.1 - continued)

\begin{tabular}{|c|c|c|c|c|}
\hline & \multicolumn{2}{|c|}{ Men } & \multicolumn{2}{|c|}{ Women } \\
\hline & Mean & S.D. & Mean & S.D. \\
\hline \multicolumn{5}{|l|}{ Occupation: } \\
\hline Managers and administrators & 0.166 & & 0.084 & \\
\hline Professional & 0.108 & & 0.105 & \\
\hline Technical & 0.102 & & 0.107 & \\
\hline Clerical and secretarial & 0.096 & & 0.293 & \\
\hline Craft & 0.184 & & 0.026 & \\
\hline Personal and protective services & 0.066 & & 0.142 & \\
\hline Sales & 0.053 & & 0.106 & \\
\hline Plant and machine operatives & 0.147 & & 0.039 & \\
\hline Other unskilled (base) & 0.078 & & 0.097 & \\
\hline \multicolumn{5}{|l|}{ Sector: } \\
\hline Private (base) & 0.763 & & 0.615 & \\
\hline Civil service & 0.049 & & 0.039 & \\
\hline Local government & 0.105 & & 0.189 & \\
\hline Other public & 0.060 & & 0.109 & \\
\hline Non-profit & 0.024 & & 0.048 & \\
\hline \multicolumn{5}{|l|}{ Firm size: } \\
\hline Fewer than 10 employees & 0.126 & & 0.199 & \\
\hline 10-24 employees & 0.135 & & 0.185 & \\
\hline 25-49 employees & 0.122 & & 0.138 & \\
\hline 50-99 employees & 0.129 & & 0.107 & \\
\hline 100-199 employees & 0.117 & & 0.097 & \\
\hline 200-499 employees & 0.169 & & 0.126 & \\
\hline 500-999 employees & 0.086 & & 0.051 & \\
\hline 1000 and more employees (base) & 0.115 & & 0.096 & \\
\hline \multicolumn{5}{|l|}{ Cohort of entry into the labour market: } \\
\hline Before 1961 (base) & 0.052 & & 0.048 & \\
\hline $1961-1970$ & 0.206 & & 0.129 & \\
\hline $1971-1980$ & 0.200 & & 0.232 & \\
\hline $1981-1990$ & 0.473 & & 0.508 & \\
\hline 1991 and after & 0.069 & & 0.083 & \\
\hline Union coverage & 0.548 & & 0.508 & \\
\hline \multicolumn{5}{|l|}{ Region: } \\
\hline Greater London (base) & 0.093 & & 0.092 & \\
\hline Rest of the South & 0.278 & & 0.285 & \\
\hline East and Center & 0.212 & & 0.198 & \\
\hline North-West & 0.115 & & 0.109 & \\
\hline North-East & 0.162 & & 0.158 & \\
\hline Wales & 0.051 & & 0.050 & \\
\hline Scotland & 0.088 & & 0.107 & \\
\hline Unemployment/vacancy ratio & 15.670 & 11.863 & 15.528 & 11.748 \\
\hline
\end{tabular}

Notes: Age groups are constructed using each worker's age at the start of the panel. $\mathrm{N}$ is number of person-wave observations. 
Table A.2a - The effect of non-standard contracts on the GHQ index by age - Men

\begin{tabular}{|c|c|c|c|c|c|c|}
\hline & \multicolumn{2}{|c|}{$<30$} & \multicolumn{2}{|c|}{$30-44$} & \multicolumn{2}{|c|}{$45+$} \\
\hline & Coeff. & S.E. & Coeff. & S.E. & Coeff. & S.E. \\
\hline \multicolumn{7}{|l|}{ OLS } \\
\hline Seas./casual (SC) & 0.376 & $(0.343)$ & 1.292 & $(1.005)$ & 0.554 & $(1.076)$ \\
\hline Fixed term $(\mathrm{FX})$ & -0.405 & $(0.334)$ & -0.941 & $(0.793)$ & $-1.385 * *$ & $(0.695)$ \\
\hline $\mathrm{N}$ & \multicolumn{2}{|c|}{4544} & \multicolumn{2}{|c|}{4769} & \multicolumn{2}{|c|}{1853} \\
\hline $\mathrm{R}^{2}$ & \multicolumn{2}{|c|}{0.0366} & \multicolumn{2}{|c|}{0.0500} & \multicolumn{2}{|c|}{0.1151} \\
\hline \multicolumn{7}{|l|}{$\mathrm{FE}$} \\
\hline Entry into SC & 0.482 & $(0.633)$ & $1.912 *$ & $(1.008)$ & -0.262 & (1.189) \\
\hline Exit from SC & $-1.240 * * *$ & $(0.462)$ & -1.052 & (1.013) & -1.212 & (1.105) \\
\hline Stay in SC & -0.437 & $(0.515)$ & 0.931 & $(1.259)$ & 1.445 & $(1.574)$ \\
\hline Entry into FX & -0.034 & $(0.580)$ & 0.375 & $(0.851)$ & -0.301 & $(0.987)$ \\
\hline Exit from FX & 0.529 & $(0.520)$ & -0.408 & $(0.810)$ & 1.357 & $(0.864)$ \\
\hline Stay in FX & 0.534 & $(0.738)$ & 0.202 & $(0.911)$ & 0.886 & $(0.961)$ \\
\hline $\mathrm{N}$ & \multirow{2}{*}{\multicolumn{2}{|c|}{$\begin{array}{c}3452 \\
0.0206\end{array}$}} & \multicolumn{2}{|c|}{3952} & \multicolumn{2}{|c|}{1505} \\
\hline $\mathrm{R}^{2}$ & & & & & 0.0 & \\
\hline \multicolumn{7}{|l|}{$\mathrm{FE}(-2)$} \\
\hline Entry into SC & $1.879 * *$ & $(0.864)$ & 1.486 & $(1.278)$ & 0.988 & $(1.662)$ \\
\hline Exit from SC & -0.897 & $(0.634)$ & 0.643 & (1.188) & 0.317 & $(1.429)$ \\
\hline Stay in SC & $1.106 *$ & $(0.665)$ & -1.912 & (1.677) & -1.694 & (1.871) \\
\hline Entry into FX & -0.442 & $(0.796)$ & 1.645 & (1.064) & -0.575 & (1.302) \\
\hline Exit from FX & -0.476 & $(0.764)$ & 0.486 & $(1.041)$ & -1.221 & $(1.224)$ \\
\hline Stay in FX & $-1.805 *$ & (1.052) & -0.357 & (1.188) & 0.172 & (1.070) \\
\hline $\mathrm{N}$ & \multicolumn{2}{|c|}{2007} & \multicolumn{2}{|c|}{2543} & \multicolumn{2}{|c|}{987} \\
\hline $\mathrm{R}^{2}$ & \multicolumn{2}{|c|}{0.0339} & \multicolumn{2}{|c|}{0.0322} & \multicolumn{2}{|c|}{0.045} \\
\hline
\end{tabular}

Notes: The base category in the OLS regressions is 'permanent contract'. For definitions and variables included in the regressions, see notes of Table 3.

$* \mathrm{p}<0.10, * * \mathrm{p}<0.05, * * \mathrm{p}<0.01$ 
Table A.2b — The effect of non-standard contracts on the GHQ index by age - Women

\begin{tabular}{|c|c|c|c|c|c|c|}
\hline & \multicolumn{2}{|c|}{$<30$} & \multicolumn{2}{|c|}{$30-44$} & \multicolumn{2}{|c|}{$45+$} \\
\hline & Coeff. & S.E. & Coeff. & S.E. & Coeff. & S.E. \\
\hline \multicolumn{7}{|l|}{ OLS } \\
\hline Seas./casual (SC) & 0.420 & $(0.320)$ & -0.029 & $(0.356)$ & -0.325 & $(0.669)$ \\
\hline Fixed term (FX) & 0.264 & $(0.455)$ & 0.003 & $(0.513)$ & -0.705 & (1.188) \\
\hline $\mathrm{N}$ & \multicolumn{2}{|c|}{5013} & \multicolumn{2}{|c|}{5253} & \multicolumn{2}{|c|}{2542} \\
\hline $\mathrm{R}^{2}$ & \multicolumn{2}{|c|}{0.0406} & \multicolumn{2}{|c|}{0.0419} & \multicolumn{2}{|c|}{0.0865} \\
\hline \multicolumn{7}{|l|}{ FE } \\
\hline Entry into SC & -0.264 & $(0.572)$ & -0.353 & $(0.584)$ & 0.717 & (1.103) \\
\hline Exit from SC & -0.237 & $(0.481)$ & 0.179 & $(0.498)$ & 0.303 & $(0.964)$ \\
\hline Stay in SC & 0.166 & $(0.647)$ & 0.093 & $(0.617)$ & -0.186 & $(1.136)$ \\
\hline Entry into FX & 0.980 & $(0.783)$ & -1.049 & $(0.687)$ & -0.151 & $(1.085)$ \\
\hline Exit from FX & -0.417 & $(0.669)$ & -0.636 & $(0.649)$ & 0.548 & $(0.915)$ \\
\hline Stay in FX & 0.925 & $(0.879)$ & 0.404 & $(0.689)$ & -0.388 & $(1.081)$ \\
\hline $\mathrm{N}$ & \multicolumn{2}{|c|}{3708} & \multicolumn{2}{|c|}{4208} & \multicolumn{2}{|c|}{2054} \\
\hline $\mathrm{R}^{2}$ & \multicolumn{2}{|c|}{0.0172} & \multicolumn{2}{|c|}{0.0215} & \multicolumn{2}{|c|}{0.0353} \\
\hline \multicolumn{7}{|l|}{$\mathrm{FE}(-2)$} \\
\hline Entry into SC & $-1.673 * *$ & $(0.815)$ & 1.133 & $(0.751)$ & 0.659 & $(1.290)$ \\
\hline Exit from SC & 0.851 & $(0.693)$ & 0.541 & $(0.641)$ & 1.209 & (1.167) \\
\hline Stay in SC & -1.391 & $(0.902)$ & -0.369 & $(0.781)$ & -0.674 & (1.509) \\
\hline Entry into FX & -1.377 & (1.163) & -0.762 & $(0.930)$ & -0.110 & (1.359) \\
\hline Exit from FX & -0.461 & $(0.953)$ & -0.482 & $(0.861)$ & -1.122 & (1.155) \\
\hline Stay in FX & 1.012 & (1.213) & -0.510 & $(0.927)$ & 0.237 & (1.496) \\
\hline $\mathrm{N}$ & \multicolumn{2}{|c|}{2240} & \multicolumn{2}{|c|}{2679} & \multicolumn{2}{|c|}{1372} \\
\hline $\mathrm{R}^{2}$ & \multicolumn{2}{|c|}{0.0243} & \multicolumn{2}{|c|}{0.0202} & \multicolumn{2}{|c|}{0.0365} \\
\hline
\end{tabular}

Notes: The base category in the OLS regressions is 'permanent contract'. For definitions and variables included in the regressions, see notes of Table 3.

$* \mathrm{p}<0.10, * * \mathrm{p}<0.05, * * \mathrm{p}<0.01$ 
Table A.3a - The effect of non-standard places on the GHQ index by age - Men

\begin{tabular}{|c|c|c|c|c|c|c|}
\hline & \multicolumn{2}{|c|}{$<30$} & \multicolumn{2}{|c|}{$30-44$} & \multicolumn{2}{|c|}{$45+$} \\
\hline & Coeff. & S.E. & Coeff. & S.E. & Coeff. & S.E. \\
\hline \multicolumn{7}{|l|}{ OLS } \\
\hline At home $(\mathrm{AH})$ & -0.375 & $(0.720)$ & 0.903 & $(1.008)$ & $3.111 *$ & $(1.538)$ \\
\hline Driving/travelling (DR) & -0.327 & $(0.304)$ & -0.045 & $(0.295)$ & $1.032 *$ & $(0.484)$ \\
\hline More than one place (M1) & -0.126 & $(0.293)$ & -0.162 & $(0.338)$ & 0.119 & $(0.544)$ \\
\hline $\mathrm{N}$ & \multicolumn{2}{|c|}{4544} & \multicolumn{2}{|c|}{4769} & \multicolumn{2}{|c|}{1853} \\
\hline $\mathrm{R}^{2}$ & \multicolumn{2}{|c|}{0.0362} & \multicolumn{2}{|c|}{0.0490} & \multicolumn{2}{|c|}{0.1200} \\
\hline \multicolumn{7}{|l|}{ FE } \\
\hline Entry into AH & -0.697 & $(2.126)$ & $1.964 * *$ & $(0.919)$ & 0.944 & $(1.722)$ \\
\hline Exit from $\mathrm{AH}$ & 1.343 & $(2.114)$ & -0.883 & $(0.990)$ & 1.250 & $(1.861)$ \\
\hline Stay in $\mathrm{AH}$ & 1.202 & $(2.347)$ & 1.022 & $(1.048)$ & 0.513 & $(1.368)$ \\
\hline Entry into DR & $-0.929 * *$ & $(0.453)$ & 0.288 & $(0.409)$ & -0.175 & $(0.539)$ \\
\hline Exit from DR & -0.335 & $(0.432)$ & -0.549 & $(0.397)$ & -0.712 & $(0.532)$ \\
\hline Stay in DR & 0.343 & $(0.338)$ & -0.121 & $(0.252)$ & 0.099 & $(0.362)$ \\
\hline Entry into M1 & -0.275 & $(0.410)$ & 0.377 & $(0.392)$ & 0.646 & $(0.571)$ \\
\hline Exit from M1 & 0.097 & $(0.437)$ & 0.406 & $(0.383)$ & 0.700 & $(0.577)$ \\
\hline Stay in M1 & 0.046 & $(0.390)$ & 0.375 & $(0.401)$ & 0.448 & $(0.542)$ \\
\hline $\mathrm{N}$ & \multicolumn{2}{|c|}{3452} & \multicolumn{2}{|c|}{3952} & \multicolumn{2}{|c|}{1505} \\
\hline $\mathrm{R}^{2}$ & \multicolumn{2}{|c|}{0.0197} & \multicolumn{2}{|c|}{0.0208} & \multicolumn{2}{|c|}{0.0485} \\
\hline \multicolumn{7}{|l|}{$\mathrm{FE}(-2)$} \\
\hline Entry into AH & 0.441 & $(2.882)$ & -1.479 & (1.171) & 3.581 & $(2.521)$ \\
\hline Exit from $\mathrm{AH}$ & -1.672 & (3.560) & 1.232 & (1.273) & 4.907 & (4.289) \\
\hline Stay in $\mathrm{AH}$ & -0.454 & $(3.456)$ & 2.163 & $(1.486)$ & -0.555 & (1.570) \\
\hline Entry into DR & 0.675 & $(0.592)$ & -0.430 & $(0.512)$ & -0.747 & $(0.686)$ \\
\hline Exit from DR & 0.682 & $(0.613)$ & 0.244 & $(0.509)$ & $1.193 *$ & $(0.668)$ \\
\hline Stay in DR & $-0.759 *$ & $(0.451)$ & -0.075 & $(0.317)$ & -0.245 & $(0.444)$ \\
\hline Entry into M1 & -0.127 & $(0.578)$ & $-1.108 * *$ & $(0.488)$ & $-1.237 *$ & (0.677) \\
\hline Exit from M1 & -0.354 & $(0.590)$ & -0.020 & $(0.462)$ & 0.379 & $(0.673)$ \\
\hline Stay in M1 & 0.869 & $(0.554)$ & -0.194 & $(0.482)$ & -0.683 & $(0.733)$ \\
\hline $\mathrm{N}$ & \multicolumn{2}{|c|}{2007} & \multicolumn{2}{|c|}{2543} & \multicolumn{2}{|c|}{987} \\
\hline $\mathrm{R}^{2}$ & \multicolumn{2}{|c|}{0.0313} & \multicolumn{2}{|c|}{0.0334} & \multicolumn{2}{|c|}{0.0534} \\
\hline
\end{tabular}

Notes: The base category in the OLS regressions is 'employer's premises'. For definitions and variables included in the regressions, see notes of Table 3.

$* \mathrm{p}<0.10, * * \mathrm{p}<0.05, * * * \mathrm{p}<0.01$. 
Table A.3b - The effect of non-standard places on the GHQ index by age - Women

\begin{tabular}{|c|c|c|c|c|c|c|}
\hline & \multicolumn{2}{|c|}{$<30$} & \multicolumn{2}{|c|}{$30-44$} & \multicolumn{2}{|c|}{$45+$} \\
\hline & Coeff. & S.E. & Coeff. & S.E. & Coeff. & S.E. \\
\hline \multicolumn{7}{|l|}{ OLS } \\
\hline At home (AH) & $-2.097 * * *$ & $(0.751)$ & -0.047 & $(0.902)$ & 0.960 & $(1.646)$ \\
\hline Driving/travelling (DR) & -0.237 & $(0.525)$ & $-0.814 *$ & $(0.469)$ & 0.627 & $(0.875)$ \\
\hline More than one place (M1) & $-0.816 *$ & $(0.462)$ & -0.125 & $(0.448)$ & 0.459 & $(0.529)$ \\
\hline $\mathrm{N}$ & \multicolumn{2}{|c|}{5013} & \multicolumn{2}{|c|}{5253} & \multicolumn{2}{|c|}{2542} \\
\hline $\mathrm{R}^{2}$ & \multicolumn{2}{|c|}{0.0422} & \multicolumn{2}{|c|}{0.0426} & \multicolumn{2}{|c|}{0.0869} \\
\hline \multicolumn{7}{|l|}{$\mathrm{FE}$} \\
\hline Entry into $\mathrm{AH}$ & 0.427 & $(1.724)$ & -0.632 & $(2.051)$ & 1.299 & $(1.739)$ \\
\hline Exit from $\mathrm{AH}$ & 0.411 & $(1.599)$ & 1.547 & $(1.325)$ & -0.129 & $(2.815)$ \\
\hline Stay in $\mathrm{AH}$ & -0.721 & (1.369) & -0.765 & $(0.927)$ & 1.537 & (1.174) \\
\hline Entry into DR & 0.342 & $(0.904)$ & -0.474 & $(0.688)$ & 0.332 & (1.133) \\
\hline Exit from DR & $1.880 * *$ & $(0.952)$ & 0.038 & $(0.726)$ & -0.677 & (1.117) \\
\hline Stay in DR & 0.585 & $(0.811)$ & 0.298 & $(0.673)$ & $2.961 *$ & $(0.946)$ \\
\hline Entry into M1 & $-1.913 * * *$ & $(0.740)$ & -0.359 & $(0.596)$ & -0.211 & $(0.774)$ \\
\hline Exit from M1 & -0.316 & $(0.741)$ & 0.067 & $(0.608)$ & -1.129 & $(0.732)$ \\
\hline Stay in M1 & -0.164 & (1.008) & -0.255 & $(0.547)$ & 0.337 & $(0.809)$ \\
\hline $\mathrm{N}$ & \multicolumn{2}{|c|}{3708} & \multicolumn{2}{|c|}{4208} & \multicolumn{2}{|c|}{2054} \\
\hline $\mathrm{R}^{2}$ & \multicolumn{2}{|c|}{0.0188} & \multicolumn{2}{|c|}{0.0213} & \multicolumn{2}{|c|}{0.042} \\
\hline \multicolumn{7}{|l|}{$\mathrm{FE}(-2)$} \\
\hline Entry into AH & 1.928 & $(2.143)$ & 3.364 & $(2.888)$ & -1.629 & (3.030) \\
\hline Exit from $\mathrm{AH}$ & -0.719 & $(2.429)$ & 0.228 & (1.616) & 3.476 & (5.356) \\
\hline Stay in $\mathrm{AH}$ & -0.278 & (1.935) & -0.609 & (1.243) & 1.670 & (1.574) \\
\hline Entry into DR & -1.031 & (1.182) & 0.026 & $(0.929)$ & -0.085 & (1.386) \\
\hline Exit from DR & 0.600 & (1.468) & -0.594 & (0.940) & -0.850 & (1.413) \\
\hline Stay in DR & -0.556 & (1.169) & -0.717 & $(0.874)$ & 1.499 & (1.380) \\
\hline Entry into M1 & 0.274 & (1.033) & -0.616 & $(0.797)$ & -0.073 & (1.046) \\
\hline Exit from M1 & $2.343 * *$ & (1.056) & 0.013 & $(0.808)$ & 0.797 & $(0.944)$ \\
\hline Stay in M1 & -0.646 & $(1.333)$ & -0.054 & $(0.759)$ & 0.779 & $(1.065)$ \\
\hline $\mathrm{N}$ & \multicolumn{2}{|c|}{2240} & \multicolumn{2}{|c|}{2679} & \multicolumn{2}{|c|}{1372} \\
\hline $\mathrm{R}^{2}$ & \multicolumn{2}{|c|}{0.0229} & \multicolumn{2}{|c|}{0.0201} & \multicolumn{2}{|c|}{0.0381} \\
\hline
\end{tabular}

Notes: The base category in the OLS regressions is 'employer's premises'. For definitions and variables included in the regressions, see notes of Table 3.

$* \mathrm{p}<0.10, * * \mathrm{p}<0.05, * * * \mathrm{p}<0.01$. 
Table A.4a - The effect of non-standard times on the GHQ index by age - Men

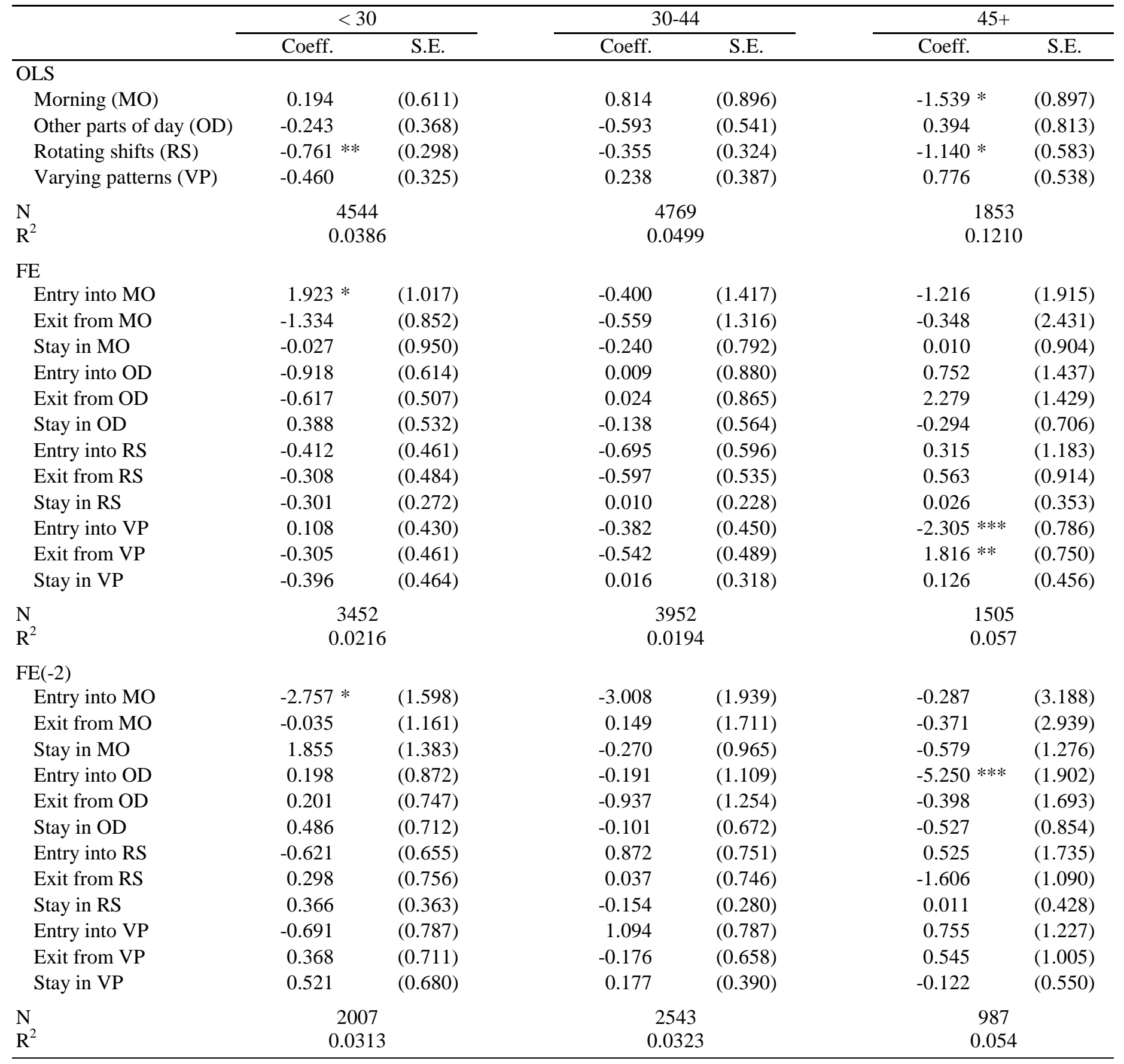

Notes: The base category in the OLS regressions is 'during the day'. For definitions and variables included in the regressions, see notes of Table 3.

$* \mathrm{p}<0.10, * * \mathrm{p}<0.05, * * * \mathrm{p}<0.01$. 
Table A.4b - The effect of non-standard times on the GHQ index by age - Women

\begin{tabular}{|c|c|c|c|c|c|c|}
\hline & \multicolumn{2}{|c|}{$<30$} & \multicolumn{2}{|c|}{ 30-44 } & \multicolumn{2}{|c|}{$45+$} \\
\hline & Coeff. & S.E. & Coeff. & S.E. & Coeff. & S.E. \\
\hline \multicolumn{7}{|l|}{ OLS } \\
\hline Morning (MO) & 0.154 & $(0.475)$ & -0.000 & $(0.324)$ & 0.043 & $(0.508)$ \\
\hline Other parts of day (OD) & -0.022 & $(0.332)$ & 0.082 & $(0.370)$ & -0.270 & $(0.510)$ \\
\hline Rotating shifts (RS) & -0.484 & $(0.373)$ & -0.248 & $(0.403)$ & 0.020 & $(0.682)$ \\
\hline Varying patterns (VP) & 0.212 & $(0.338)$ & $-1.514 * * *$ & $(0.294)$ & 0.289 & $(0.552)$ \\
\hline $\begin{array}{l}\mathrm{N} \\
\mathrm{R}^{2}\end{array}$ & \multicolumn{2}{|c|}{$\begin{array}{c}5013 \\
0.0409\end{array}$} & \multicolumn{2}{|c|}{5253} & & \\
\hline \multicolumn{7}{|l|}{$\mathrm{FE}$} \\
\hline Entry into MO & 0.567 & $(0.811)$ & $-0.989 *$ & $(0.566)$ & -1.157 & $(0.749)$ \\
\hline Exit from MO & -1.133 & $(0.803)$ & $-1.374 * * *$ & $(0.520)$ & -0.361 & $(0.779)$ \\
\hline Stay in MO & -0.225 & $(0.693)$ & -0.197 & $(0.325)$ & -0.040 & $(0.392)$ \\
\hline Entry into OD & -0.250 & $(0.638)$ & $-1.191 *$ & $(0.725)$ & -1.239 & $(0.990)$ \\
\hline Exit from OD & -0.199 & $(0.523)$ & -0.405 & $(0.537)$ & 0.943 & $(0.918)$ \\
\hline Stay in OD & 0.615 & $(0.453)$ & -0.050 & $(0.326)$ & 0.044 & $(0.411)$ \\
\hline Entry into RS & 0.348 & $(0.764)$ & $-1.305 *$ & $(0.715)$ & -0.581 & $(0.990)$ \\
\hline Exit from RS & -0.319 & $(0.680)$ & 0.331 & $(0.673)$ & -1.499 & $(1.000)$ \\
\hline Stay in RS & 0.210 & $(0.402)$ & $0.746 *$ & $(0.425)$ & 0.418 & $(0.587)$ \\
\hline Entry into VP & -0.229 & $(0.561)$ & -0.535 & $(0.509)$ & 0.252 & $(0.710)$ \\
\hline Exit from VP & 0.734 & $(0.572)$ & $1.504 * * *$ & $(0.521)$ & 0.144 & $(0.677)$ \\
\hline Stay in VP & 0.427 & $(0.600)$ & 0.181 & $(0.379)$ & 0.540 & $(0.461)$ \\
\hline $\begin{array}{l}\mathrm{N} \\
\mathrm{R}^{2}\end{array}$ & \multicolumn{2}{|c|}{3708} & \multicolumn{2}{|c|}{0.0273} & \multicolumn{2}{|c|}{0.0399} \\
\hline \multicolumn{7}{|l|}{$\mathrm{FE}(-2)$} \\
\hline Entry into MO & $-2.354 * *$ & (1.084) & -0.480 & $(0.851)$ & -0.754 & $(1.045)$ \\
\hline Exit from MO & 0.790 & (1.258) & $1.384 *$ & $(0.746)$ & -0.853 & (1.089) \\
\hline Stay in MO & 1.179 & $(1.035)$ & -0.096 & $(0.423)$ & -0.336 & $(0.506)$ \\
\hline Entry into OD & -0.449 & $(0.856)$ & -0.380 & (1.011) & -0.947 & $(1.408)$ \\
\hline Exit from OD & 0.226 & $(0.746)$ & 0.779 & $(0.748)$ & 0.498 & $(1.369)$ \\
\hline Stay in OD & -0.696 & $(0.609)$ & 0.482 & $(0.407)$ & 0.100 & $(0.527)$ \\
\hline Entry into RS & 0.890 & (1.101) & 0.523 & $(0.968)$ & 1.558 & (1.614) \\
\hline Exit from RS & -0.066 & (0.990) & 0.480 & (1.085) & -1.695 & (1.685) \\
\hline Stay in RS & 0.023 & $(0.525)$ & 0.357 & $(0.546)$ & -0.289 & $(0.718)$ \\
\hline Entry into VP & -0.676 & (1.020) & 0.089 & $(0.934)$ & 1.237 & (1.299) \\
\hline Exit from VP & 1.057 & $(0.815)$ & 0.661 & (0.719) & -0.146 & $(1.046)$ \\
\hline Stay in VP & -0.543 & $(0.878)$ & 0.434 & $(0.466)$ & -0.306 & $(0.570)$ \\
\hline $\mathrm{N}$ & \multirow{2}{*}{\multicolumn{2}{|c|}{$\begin{array}{c}2240 \\
0.0247\end{array}$}} & \multirow{2}{*}{\multicolumn{2}{|c|}{$\begin{array}{c}2679 \\
0.0217\end{array}$}} & \multirow{2}{*}{\multicolumn{2}{|c|}{$\begin{array}{c}1372 \\
0.0388\end{array}$}} \\
\hline $\mathrm{R}^{2}$ & & & & & & \\
\hline
\end{tabular}

Notes: The base category in the OLS regressions is 'during the day'. For definitions and variables included in the regressions, see notes of Table 3.

$* \mathrm{p}<0.10, * * \mathrm{p}<0.05, * * * \mathrm{p}<0.01$. 
Table A.5a - The effect of non-standard hours on the GHQ index by age - Men

\begin{tabular}{|c|c|c|c|c|c|c|}
\hline & \multicolumn{2}{|c|}{$<30$} & \multicolumn{2}{|c|}{$30-44$} & \multicolumn{2}{|c|}{$45+$} \\
\hline & Coeff. & S.E. & Coeff. & S.E. & Coeff. & S.E. \\
\hline \multicolumn{7}{|l|}{ OLS } \\
\hline Long hours (LH) & -0.333 & $(0.210)$ & -0.187 & $(0.222)$ & 0.039 & $(0.363)$ \\
\hline Medium hours (MH) & 0.311 & $(0.503)$ & 0.532 & $(1.032)$ & -1.553 & $(1.028)$ \\
\hline Short hours (SH) & 0.350 & $(0.436)$ & 1.995 & $(1.718)$ & -0.126 & $(1.865)$ \\
\hline $\mathrm{N}$ & \multicolumn{2}{|c|}{4544} & \multicolumn{2}{|c|}{4769} & \multicolumn{2}{|c|}{1853} \\
\hline $\mathrm{R}^{2}$ & \multicolumn{2}{|c|}{0.0371} & \multicolumn{2}{|c|}{0.0498} & \multicolumn{2}{|c|}{0.1139} \\
\hline \multicolumn{7}{|l|}{ FE } \\
\hline Entry into LH & -0.270 & $(0.273)$ & 0.014 & $(0.283)$ & -0.008 & $(0.395)$ \\
\hline Exit from $\mathrm{LH}$ & 0.396 & $(0.289)$ & 0.017 & $(0.282)$ & -0.166 & $(0.401)$ \\
\hline Stay in LH & -0.124 & $(0.214)$ & -0.252 & $(0.183)$ & -0.092 & $(0.265)$ \\
\hline Entry into MH & 0.510 & $(0.786)$ & -1.706 & $(1.515)$ & -2.758 & (1.943) \\
\hline Exit from MH & 0.161 & $(0.661)$ & -0.833 & (1.147) & 2.301 & $(1.742)$ \\
\hline Stay in $\mathrm{MH}$ & 1.282 & $(0.886)$ & 0.777 & $(1.385)$ & -1.182 & $(1.508)$ \\
\hline Entry into SH & -0.700 & $(0.991)$ & 2.168 & $(1.873)$ & 0.507 & $(2.363)$ \\
\hline Exit from $\mathrm{SH}$ & $-1.251 * *$ & $(0.594)$ & 2.139 & $(1.708)$ & 0.866 & (2.096) \\
\hline Stay in SH & $1.009 *$ & $(0.543)$ & 0.512 & (1.982) & 1.408 & (1.864) \\
\hline $\mathrm{N}$ & \multicolumn{2}{|c|}{3452} & \multicolumn{2}{|c|}{3952} & \multicolumn{2}{|c|}{1505} \\
\hline $\mathrm{R}^{2}$ & \multicolumn{2}{|c|}{0.0217} & \multicolumn{2}{|c|}{0.0196} & \multicolumn{2}{|c|}{0.0497} \\
\hline \multicolumn{7}{|l|}{$\mathrm{FE}(-2)$} \\
\hline Entry into LH & -0.233 & $(0.390)$ & -0.110 & $(0.348)$ & -0.260 & $(0.471)$ \\
\hline Exit from LH & 0.461 & (0.409) & -0.369 & $(0.342)$ & $0.852 *$ & $(0.495)$ \\
\hline Stay in LH & 0.196 & $(0.295)$ & -0.077 & $(0.233)$ & 0.503 & $(0.339)$ \\
\hline Entry into MH & -0.867 & (0.966) & -0.096 & (1.892) & 2.231 & (2.517) \\
\hline Exit from MH & 0.006 & (1.021) & -0.414 & (1.383) & n.a. & \\
\hline Stay in $\mathrm{MH}$ & -0.639 & (1.350) & 1.033 & (1.703) & 0.701 & (2.067) \\
\hline Entry into SH & 1.303 & (1.620) & -2.472 & (2.832) & 6.546 & (4.487) \\
\hline Exit from $\mathrm{SH}$ & -1.048 & $(0.759)$ & -1.625 & $(2.178)$ & -0.453 & (3.007) \\
\hline Stay in SH & $1.437 * *$ & $(0.647)$ & -0.101 & $(2.243)$ & -0.624 & $(2.510)$ \\
\hline $\mathrm{N}$ & \multicolumn{2}{|c|}{2007} & \multicolumn{2}{|c|}{2543} & \multicolumn{2}{|c|}{987} \\
\hline $\mathrm{R}^{2}$ & \multicolumn{2}{|c|}{0.0336} & \multicolumn{2}{|c|}{0.0309} & \multicolumn{2}{|c|}{0.0512} \\
\hline
\end{tabular}

Notes: The base category in the OLS regressions is 'normal hours' (30-48 per week). For definitions and variables included in the regressions, see notes of Table 3.

$* \mathrm{p}<0.10, * * \mathrm{p}<0.05, * * * \mathrm{p}<0.01-\mathrm{n} . \mathrm{a} .=$ estimate not available. 
Table A.5b - The effect of non-standard hours on the GHQ index by age - Women

\begin{tabular}{|c|c|c|c|c|c|c|}
\hline & \multicolumn{2}{|c|}{$<30$} & \multicolumn{2}{|c|}{$30-44$} & \multicolumn{2}{|c|}{$45+$} \\
\hline & Coeff. & S.E. & Coeff. & S.E. & Coeff. & S.E. \\
\hline \multicolumn{7}{|l|}{ OLS } \\
\hline Long hours (LH) & 0.048 & $(0.333)$ & -0.083 & $(0.358)$ & 1.236 & $(0.804)$ \\
\hline Medium hours (MH) & -0.199 & $(0.288)$ & $0.469 *$ & $(0.270)$ & -0.074 & $(0.404)$ \\
\hline Short hours (SH) & 0.415 & $(0.317)$ & -0.005 & $(0.322)$ & -0.163 & $(0.537)$ \\
\hline $\mathrm{N}$ & \multicolumn{2}{|c|}{5013} & \multicolumn{2}{|c|}{5253} & \multicolumn{2}{|c|}{2542} \\
\hline $\mathrm{R}^{2}$ & \multicolumn{2}{|c|}{0.0411} & \multicolumn{2}{|c|}{0.0432} & \multicolumn{2}{|c|}{0.0889} \\
\hline \multicolumn{7}{|l|}{$\mathrm{FE}$} \\
\hline Entry into LH & 0.419 & $(0.508)$ & -0.115 & $(0.479)$ & -0.340 & $(0.692)$ \\
\hline Exit from LH & -0.113 & $(0.530)$ & 0.017 & $(0.495)$ & -0.068 & $(0.736)$ \\
\hline Stay in LH & -0.168 & $(0.525)$ & $0.817 * *$ & $(0.394)$ & 0.789 & $(0.545)$ \\
\hline Entry into $\mathrm{MH}$ & 0.809 & $(0.523)$ & 0.248 & $(0.470)$ & $-1.679 * *$ & $(0.696)$ \\
\hline Exit from MH & 0.034 & $(0.487)$ & -0.450 & $(0.410)$ & -0.213 & $(0.664)$ \\
\hline Stay in $\mathrm{MH}$ & $0.911 * *$ & $(0.455)$ & -0.529 & $(0.365)$ & $-0.868 *$ & $(0.487)$ \\
\hline Entry into SH & $1.746 * * *$ & $(0.655)$ & -0.541 & $(0.627)$ & -0.157 & (0.936) \\
\hline Exit from $\mathrm{SH}$ & -0.516 & $(0.517)$ & -0.464 & $(0.525)$ & 0.639 & $(0.848)$ \\
\hline Stay in SH & 0.544 & $(0.413)$ & -0.460 & $(0.390)$ & -0.667 & $(0.523)$ \\
\hline $\mathrm{N}$ & \multicolumn{2}{|c|}{3708} & \multicolumn{2}{|c|}{4208} & \multicolumn{2}{|c|}{2054} \\
\hline $\mathrm{R}^{2}$ & \multicolumn{2}{|c|}{0.0196} & \multicolumn{2}{|c|}{0.0229} & \multicolumn{2}{|c|}{0.0392} \\
\hline \multicolumn{7}{|l|}{$\mathrm{FE}(-2)$} \\
\hline Entry into LH & 0.585 & $(0.699)$ & -0.010 & $(0.608)$ & 1.268 & $(0.837)$ \\
\hline Exit from LH & -0.615 & $(0.745)$ & -1.080 & $(0.697)$ & -0.042 & (0.959) \\
\hline Stay in LH & -0.255 & $(0.789)$ & 0.845 & $(0.533)$ & 0.039 & $(0.727)$ \\
\hline Entry into $\mathrm{MH}$ & 0.278 & $(0.696)$ & -0.442 & $(0.615)$ & 1.501 & $(0.921)$ \\
\hline Exit from MH & -0.303 & $(0.703)$ & -0.105 & $(0.573)$ & $1.576 *$ & $(0.831)$ \\
\hline Stay in MH & -0.721 & $(0.632)$ & $0.826 *$ & $(0.482)$ & -0.002 & (0.639) \\
\hline Entry into SH & -0.917 & $(0.869)$ & 1.043 & $(0.831)$ & $2.186 *$ & (1.149) \\
\hline Exit from SH & $1.402 *$ & $(0.734)$ & -0.006 & $(0.713)$ & -0.368 & (1.079) \\
\hline Stay in SH & -0.770 & $(0.535)$ & $0.898 *$ & $(0.499)$ & 0.765 & $(0.682)$ \\
\hline $\mathrm{N}$ & \multicolumn{2}{|c|}{2240} & \multicolumn{2}{|c|}{2679} & \multicolumn{2}{|c|}{1372} \\
\hline $\mathrm{R}^{2}$ & \multicolumn{2}{|c|}{0.0263} & \multicolumn{2}{|c|}{0.0248} & \multicolumn{2}{|c|}{0.0492} \\
\hline
\end{tabular}

Notes: The base category in the OLS regressions is 'normal hours' (30-48 per week). For definitions and variables included in the regressions, see notes of Table 3.

$* \mathrm{p}<0.10, * * \mathrm{p}<0.05, * * \mathrm{p}<0.01$. 
Table A.6a - The effect of non-standard contracts on the GHQ index by education - Men

\begin{tabular}{|c|c|c|c|c|c|c|c|c|}
\hline & \multicolumn{2}{|c|}{$<$ O-level } & \multicolumn{2}{|c|}{ O-level } & \multicolumn{2}{|c|}{ A-level } & \multicolumn{2}{|c|}{$>$ A-level } \\
\hline & Coeff. & S.E. & Coeff. & S.E. & Coeff. & S.E. & Coeff. & S.E. \\
\hline \multicolumn{9}{|l|}{$\overline{\text { OLS }}$} \\
\hline Seas./casual (SC) & 0.823 & $(0.750)$ & 0.070 & $(0.459)$ & -0.061 & $(0.722)$ & $2.177 * *$ & $(0.925)$ \\
\hline $\begin{array}{l}\mathrm{N} \\
\mathrm{R}^{2}\end{array}$ & \multicolumn{2}{|c|}{2782} & \multicolumn{2}{|c|}{2796} & \multicolumn{2}{|c|}{1805} & 0.0691 & 3783 \\
\hline \multicolumn{9}{|l|}{ FE } \\
\hline Entry into SC & -1.008 & $(0.904)$ & 0.085 & $(0.810)$ & -1.036 & $(1.274)$ & $4.116 * * *$ & $(1.059)$ \\
\hline Exit from SC & -1.041 & $(0.798)$ & -0.426 & $(0.594)$ & $-1.726 *$ & $(0.971)$ & $-1.869 * *$ & $(0.931)$ \\
\hline Stay in SC & 0.018 & (1.070) & -0.071 & $(0.605)$ & -0.998 & $(1.056)$ & -0.581 & $(1.475)$ \\
\hline Entry into FX & 0.808 & $(0.868)$ & $-1.206 *$ & $(0.691)$ & $2.328 *$ & $(1.211)$ & -0.259 & $(0.879)$ \\
\hline Exit from FX & 0.207 & $(0.757)$ & $1.345 * *$ & $(0.677)$ & -0.036 & (1.006) & -0.117 & $(0.763)$ \\
\hline Stay in FX & 0.582 & (1.111) & 0.553 & (1.047) & 2.445 & $(1.545)$ & -0.263 & $(0.737)$ \\
\hline $\mathrm{N}$ & \multicolumn{2}{|c|}{2204} & \multicolumn{2}{|c|}{2165} & \multicolumn{2}{|c|}{1432} & \multicolumn{2}{|c|}{3108} \\
\hline $\mathrm{R}^{2}$ & \multicolumn{2}{|c|}{0.0361} & \multicolumn{2}{|c|}{0.0400} & \multicolumn{2}{|c|}{0.0741} & \multicolumn{2}{|c|}{0.0275} \\
\hline \multicolumn{9}{|l|}{$\mathrm{FE}(-2)$} \\
\hline Entry into SC & $2.865 *$ & $(1.274)$ & 0.626 & (1.178) & 0.917 & $(1.736)$ & $2.648 * *$ & $(1.268)$ \\
\hline Exit from SC & -0.183 & (1.093) & -0.607 & $(0.819)$ & $2.504 * *$ & (1.268) & -0.733 & $(1.248)$ \\
\hline Stay in SC & -0.896 & $(1.285)$ & $1.490 *$ & $(0.857)$ & 1.019 & (1.238) & -1.077 & $(1.824)$ \\
\hline Entry into FX & -1.146 & (1.292) & -1.196 & $(0.930)$ & 0.285 & (1.701) & $3.067 * * *$ & (1.097) \\
\hline Exit from FX & -1.579 & (1.048) & -0.611 & (1.053) & $3.044 * *$ & (1.527) & 0.308 & $(0.981)$ \\
\hline Stay in FX & 0.864 & (1.426) & -1.539 & (1.703) & $-3.954 * *$ & (1.911) & -0.003 & $(0.893)$ \\
\hline $\mathrm{N}$ & \multicolumn{2}{|c|}{1365} & \multicolumn{2}{|c|}{1307} & \multicolumn{2}{|c|}{880} & \multicolumn{2}{|l|}{1985} \\
\hline $\mathrm{R}^{2}$ & \multicolumn{2}{|c|}{0.0387} & \multicolumn{2}{|c|}{0.0433} & \multicolumn{2}{|c|}{0.0634} & \multicolumn{2}{|c|}{0.0280} \\
\hline
\end{tabular}

Notes: The base category in the OLS regressions is 'permanent contract'. For definitions and variables included in the regressions, see notes of Table 3.

$* \mathrm{p}<0.10, * * \mathrm{p}<0.05, * * * \mathrm{p}<0.01$ 
Table A.6b - The effect of non-standard contracts on the GHQ index by education - Women

\begin{tabular}{|c|c|c|c|c|c|c|c|c|}
\hline & \multicolumn{2}{|c|}{$<$ O-level } & \multicolumn{2}{|c|}{ O-level } & \multicolumn{2}{|c|}{ A-level } & \multicolumn{2}{|c|}{$>$ A-level } \\
\hline & Coeff. & S.E. & Coeff. & S.E. & Coeff. & S.E. & Coeff. & S.E. \\
\hline \multicolumn{9}{|l|}{ OLS } \\
\hline Seas./casual (SC) & -0.089 & $(0.414)$ & 0.164 & $(0.333)$ & 0.560 & $(0.670)$ & 0.418 & $(0.513)$ \\
\hline $\begin{array}{l}\mathrm{N} \\
\mathrm{R}^{2}\end{array}$ & \multicolumn{2}{|c|}{0.0716} & \multicolumn{2}{|c|}{0.0531} & \multicolumn{2}{|c|}{0.0809} & \multicolumn{2}{|c|}{3390} \\
\hline \multicolumn{9}{|l|}{$\mathrm{FE}$} \\
\hline Entry into SC & -0.422 & $(0.676)$ & -0.074 & $(0.565)$ & -1.494 & $(1.231)$ & 0.605 & $(0.928)$ \\
\hline Exit from SC & -0.454 & $(0.572)$ & -0.288 & $(0.497)$ & 0.461 & $(0.995)$ & 0.657 & $(0.747)$ \\
\hline Stay in SC & -0.218 & $(0.713)$ & 0.084 & $(0.630)$ & $2.358 *$ & (1.241) & -1.629 & (1.034) \\
\hline Entry into FX & -0.771 & $(1.075)$ & 0.740 & $(0.804)$ & 2.738 & (1.727) & -0.956 & $(0.777)$ \\
\hline Exit from FX & -1.104 & $(0.853)$ & -0.816 & $(0.728)$ & -1.435 & $(1.640)$ & 0.508 & $(0.704)$ \\
\hline Stay in FX & $3.133 * *$ & $(1.381)$ & 0.606 & (1.069) & -0.102 & $(1.696)$ & 0.107 & $(0.685)$ \\
\hline $\mathrm{N}$ & \multicolumn{2}{|c|}{2994} & \multicolumn{2}{|c|}{3187} & \multicolumn{2}{|c|}{1061} & \multicolumn{2}{|c|}{2728} \\
\hline $\mathrm{R}^{2}$ & \multicolumn{2}{|c|}{0.0312} & \multicolumn{2}{|c|}{0.0230} & \multicolumn{2}{|c|}{0.0702} & \multicolumn{2}{|c|}{0.0200} \\
\hline \multicolumn{9}{|l|}{$\mathrm{FE}(-2)$} \\
\hline Entry into SC & 0.398 & $(0.885)$ & 0.689 & $(0.745)$ & $-5.503 * * *$ & $(1.810)$ & 0.736 & (1.196) \\
\hline Exit from SC & 0.548 & $(0.803)$ & -0.193 & $(0.636)$ & 1.336 & $(1.480)$ & $2.381 *$ & $(0.989)$ \\
\hline Stay in SC & -1.667 & $(1.015)$ & -0.703 & $(0.825)$ & -1.461 & (1.658) & -0.117 & $(1.255)$ \\
\hline Entry into FX & 0.274 & (1.486) & -1.442 & (1.104) & $-5.746 * *$ & $(2.723)$ & -0.734 & (1.043) \\
\hline Exit from FX & 1.260 & (1.121) & -0.041 & (1.048) & 2.501 & $(2.458)$ & $-1.651 *$ & $(0.896)$ \\
\hline Stay in FX & -0.516 & (1.976) & -1.769 & $(1.375)$ & 1.179 & $(2.466)$ & 0.432 & $(0.916)$ \\
\hline $\mathrm{N}$ & \multicolumn{2}{|c|}{1895} & \multicolumn{2}{|c|}{1999} & \multicolumn{2}{|c|}{656} & \multicolumn{2}{|c|}{1741} \\
\hline $\mathrm{R}^{2}$ & \multicolumn{2}{|c|}{0.0361} & \multicolumn{2}{|c|}{0.0345} & \multicolumn{2}{|c|}{0.1021} & \multicolumn{2}{|c|}{0.0266} \\
\hline
\end{tabular}

Notes: The base category in the OLS regressions is 'permanent contract'. For definitions and variables included in the regressions, see notes of Table 3.

$* \mathrm{p}<0.10, * * \mathrm{p}<0.05, * * * \mathrm{p}<0.01$. 
Table A.7a - The effect of non-standard places on the GHQ index by education - Men

\begin{tabular}{|c|c|c|c|c|c|c|c|c|}
\hline & \multicolumn{2}{|c|}{$<$ O-level } & \multicolumn{2}{|c|}{ O-level } & \multicolumn{2}{|c|}{ A-level } & \multicolumn{2}{|c|}{$>$ A-level } \\
\hline & Coeff. & S.E. & Coeff. & S.E. & Coeff. & S.E. & Coeff. & S.E. \\
\hline \multicolumn{9}{|l|}{ OLS } \\
\hline At home (AH) & -1.395 & $(1.341)$ & 0.021 & $(1.216)$ & $-3.519 * * *$ & $(1.324)$ & 1.459 & $(0.930)$ \\
\hline Driving/travelling (DR) & -0.404 & $(0.355)$ & -0.042 & $(0.340)$ & 0.175 & $(0.628)$ & $0.793 * *$ & $(0.348)$ \\
\hline More than one place (M1) & -0.213 & $(0.410)$ & 0.016 & $(0.378)$ & 0.471 & $(0.527)$ & -0.137 & $(0.338)$ \\
\hline $\mathrm{N}$ & \multicolumn{2}{|c|}{2782} & \multicolumn{2}{|c|}{2796} & \multicolumn{2}{|c|}{1805} & \multicolumn{2}{|c|}{3783} \\
\hline $\mathrm{R}^{2}$ & \multicolumn{2}{|c|}{0.0882} & \multicolumn{2}{|c|}{0.0758} & \multicolumn{2}{|c|}{0.1072} & \multicolumn{2}{|c|}{0.0685} \\
\hline \multicolumn{9}{|l|}{$\mathrm{FE}$} \\
\hline Entry into AH & 0.035 & $(2.974)$ & 0.414 & $(1.772)$ & 1.511 & $(2.694)$ & $1.597 *$ & $(0.970)$ \\
\hline Exit from $\mathrm{AH}$ & -0.195 & $(4.210)$ & 2.203 & $(2.116)$ & 3.048 & $(3.322)$ & -1.017 & $(0.983)$ \\
\hline Stay in $\mathrm{AH}$ & 0.999 & $(2.425)$ & -0.844 & $(1.890)$ & -1.830 & $(3.295)$ & 1.473 & (1.024) \\
\hline Entry into DR & -0.516 & $(0.480)$ & $-1.067 * *$ & $(0.517)$ & 0.119 & $(0.700)$ & 0.310 & $(0.494)$ \\
\hline Exit from DR & -0.504 & $(0.456)$ & -0.578 & $(0.484)$ & $-1.174 *$ & $(0.680)$ & -0.053 & $(0.493)$ \\
\hline Stay in DR & 0.203 & $(0.267)$ & -0.035 & $(0.340)$ & 0.204 & $(0.498)$ & -0.290 & $(0.407)$ \\
\hline Entry into M1 & -0.684 & $(0.533)$ & 0.477 & $(0.517)$ & 0.696 & $(0.645)$ & -0.034 & $(0.417)$ \\
\hline Exit from M1 & 0.146 & $(0.518)$ & 0.774 & $(0.556)$ & -0.128 & $(0.632)$ & 0.427 & $(0.426)$ \\
\hline Stay in M1 & 0.427 & $(0.514)$ & 0.522 & $(0.524)$ & -0.012 & $(0.632)$ & 0.119 & $(0.403)$ \\
\hline $\mathrm{N}$ & \multicolumn{2}{|c|}{2204} & \multicolumn{2}{|c|}{2165} & \multicolumn{2}{|c|}{1432} & \multicolumn{2}{|c|}{3108} \\
\hline $\mathrm{R}^{2}$ & \multicolumn{2}{|c|}{0.0377} & \multicolumn{2}{|c|}{0.0397} & \multicolumn{2}{|c|}{0.0704} & \multicolumn{2}{|c|}{0.0238} \\
\hline \multicolumn{9}{|l|}{$\mathrm{FE}(-2)$} \\
\hline Entry into AH & n.a. & & -2.322 & (2.319) & -1.798 & $(3.276)$ & -1.050 & $(1.233)$ \\
\hline Exit from $\mathrm{AH}$ & n.a. & & -0.626 & $(3.724)$ & n.a. & & 1.441 & $(1.262)$ \\
\hline Stay in AH & -0.008 & (3.097) & 3.271 & (2.918) & n.a. & & 0.267 & $(1.271)$ \\
\hline Entry into DR & -0.757 & $(0.614)$ & 0.584 & $(0.702)$ & -0.850 & $(0.899)$ & 0.383 & $(0.614)$ \\
\hline Exit from DR & 0.427 & $(0.595)$ & 0.503 & $(0.718)$ & 0.472 & $(0.870)$ & 0.997 & $(0.630)$ \\
\hline Stay in DR & -0.195 & $(0.354)$ & -0.404 & $(0.454)$ & 0.115 & $(0.624)$ & -0.703 & $(0.504)$ \\
\hline Entry into M1 & 0.687 & $(0.677)$ & $-1.739 * *$ & $(0.769)$ & -0.670 & $(0.771)$ & $-1.038 * *$ & $(0.519)$ \\
\hline Exit from M1 & 0.211 & $(0.660)$ & -0.421 & $(0.743)$ & $1.612 * *$ & $(0.811)$ & -0.704 & $(0.509)$ \\
\hline Stay in M1 & 0.221 & $(0.685)$ & 0.441 & $(0.761)$ & -0.712 & $(0.780)$ & 0.210 & $(0.513)$ \\
\hline $\mathrm{N}$ & \multicolumn{2}{|c|}{1365} & \multicolumn{2}{|c|}{1307} & \multicolumn{2}{|c|}{880} & \multicolumn{2}{|c|}{1985} \\
\hline $\mathrm{R}^{2}$ & \multicolumn{2}{|c|}{0.0363} & \multicolumn{2}{|c|}{0.0442} & 0.05 & & 0.02 & \\
\hline
\end{tabular}

Notes: The base category in the OLS regressions is 'employer's premises'. For definitions and variables included in the regressions, see notes of Table 3.

$* \mathrm{p}<0.10, * * \mathrm{p}<0.05, * * * \mathrm{p}<0.01-\mathrm{n} . \mathrm{a} .=$ estimate not available. 
Table A.7b — The effect of non-standard places on health status, by education level - Women

\begin{tabular}{|c|c|c|c|c|c|c|c|c|}
\hline & \multicolumn{2}{|c|}{ < O-level } & \multicolumn{2}{|c|}{ O-level } & \multicolumn{2}{|c|}{ A-level } & \multicolumn{2}{|c|}{$>$ A-level } \\
\hline & Coeff. & S.E. & Coeff. & S.E. & Coeff. & S.E. & Coeff. & S.E. \\
\hline \multicolumn{9}{|l|}{ OLS } \\
\hline At home (AH) & $-1.637 * * *$ & $(0.631)$ & $-2.404 * *$ & $(1.029)$ & 1.135 & $(1.601)$ & $2.499 *$ & $(1.324)$ \\
\hline Driving/travelling (DR) & 1.021 & $(0.757)$ & $-1.067 * *$ & $(0.536)$ & 0.169 & $(1.429)$ & -0.039 & $(0.514)$ \\
\hline More than one place (M1) & -0.375 & $(0.638)$ & $-1.292 * *$ & $(0.550)$ & -0.313 & $(0.684)$ & 0.649 & $(0.416)$ \\
\hline $\mathrm{N}$ & \multicolumn{2}{|c|}{3867} & \multicolumn{2}{|c|}{4136} & \multicolumn{2}{|c|}{1415} & \multicolumn{2}{|c|}{3390} \\
\hline $\mathrm{R}^{2}$ & \multicolumn{2}{|c|}{0.0735} & \multicolumn{2}{|c|}{0.0577} & \multicolumn{2}{|c|}{0.0803} & \multicolumn{2}{|c|}{0.0456} \\
\hline \multicolumn{9}{|l|}{$\mathrm{FE}$} \\
\hline Entry into AH & -0.308 & $(1.811)$ & -2.801 & $(2.222)$ & 3.849 & $(2.777)$ & 0.792 & $(2.119)$ \\
\hline Exit from $\mathrm{AH}$ & 2.552 & $(1.628)$ & -0.219 & $(1.444)$ & -0.509 & $(3.586)$ & 0.833 & $(2.230)$ \\
\hline Stay in $\mathrm{AH}$ & -1.330 & $(1.205)$ & 0.002 & (1.117) & -1.452 & $(1.708)$ & 0.808 & $(1.472)$ \\
\hline Entry into DR & -0.366 & $(0.992)$ & -0.755 & $(0.903)$ & 2.850 & $(1.756)$ & 0.134 & $(0.826)$ \\
\hline Exit from DR & 1.097 & $(0.965)$ & 0.619 & (1.046) & $-3.844 * *$ & (1.803) & $1.487 *$ & $(0.852)$ \\
\hline Stay in DR & 0.945 & $(0.754)$ & 0.818 & $(0.905)$ & -0.155 & $(2.698)$ & 0.791 & $(0.770)$ \\
\hline Entry into M1 & $-1.812 * *$ & $(0.722)$ & -0.870 & $(0.841)$ & 0.144 & $(1.365)$ & -0.538 & $(0.671)$ \\
\hline Exit from M1 & -0.142 & $(0.718)$ & 0.095 & $(0.875)$ & -1.260 & (1.430) & -0.585 & $(0.660)$ \\
\hline Stay in M1 & -0.293 & $(0.726)$ & -0.440 & $(0.996)$ & -0.930 & (1.819) & 0.263 & $(0.665)$ \\
\hline $\mathrm{N}$ & \multicolumn{2}{|c|}{2994} & \multicolumn{2}{|c|}{3187} & \multicolumn{2}{|c|}{1061} & \multicolumn{2}{|c|}{2728} \\
\hline $\mathrm{R}^{2}$ & \multicolumn{2}{|c|}{0.0324} & \multicolumn{2}{|c|}{0.0235} & \multicolumn{2}{|c|}{0.0707} & \multicolumn{2}{|c|}{0.0201} \\
\hline \multicolumn{9}{|l|}{$\mathrm{FE}(-2)$} \\
\hline Entry into AH & 1.229 & $(2.507)$ & -2.190 & $(2.781)$ & 4.212 & $(5.242)$ & 0.932 & $(2.792)$ \\
\hline Exit from $\mathrm{AH}$ & 1.012 & $(2.153)$ & -0.536 & (1.986) & 2.093 & $(7.095)$ & 1.555 & $(2.745)$ \\
\hline Stay in AH & 0.390 & (1.677) & 0.634 & $(1.482)$ & 1.823 & $(2.336)$ & -2.905 & $(2.044)$ \\
\hline Entry into DR & -0.967 & (1.261) & -1.519 & (1.242) & 2.246 & (2.369) & 0.072 & $(1.058)$ \\
\hline Exit from DR & 0.091 & (1.264) & -0.832 & $(1.452)$ & $-5.376 * *$ & $(2.552)$ & 0.991 & $(1.143)$ \\
\hline Stay in DR & 0.043 & (1.031) & 0.362 & (1.205) & -2.263 & $(4.805)$ & -0.794 & (1.038) \\
\hline Entry into M1 & -1.493 & (1.063) & 1.347 & (1.069) & -0.344 & (1.925) & -0.672 & $(0.886)$ \\
\hline Exit from M1 & 1.235 & $(0.998)$ & 0.372 & (1.100) & 1.392 & $(2.025)$ & 0.824 & $(0.888)$ \\
\hline Stay in M1 & -0.368 & $(0.984)$ & -1.951 & $(1.421)$ & 0.552 & (2.789) & 0.917 & $(0.867)$ \\
\hline $\mathrm{N}$ & \multirow{2}{*}{\multicolumn{2}{|c|}{$\begin{array}{c}1895 \\
0.0359\end{array}$}} & \multirow{2}{*}{\multicolumn{2}{|c|}{$\begin{array}{c}1999 \\
0.0349\end{array}$}} & \multirow{2}{*}{\multicolumn{2}{|c|}{$\begin{array}{c}656 \\
0.0939\end{array}$}} & \multirow{2}{*}{\multicolumn{2}{|c|}{$\begin{array}{c}1741 \\
0.0246\end{array}$}} \\
\hline $\mathrm{R}^{2}$ & & & & & & & & \\
\hline
\end{tabular}

Notes: The base category in the OLS regressions is 'employer's premises'. For definitions and variables included in the regressions, see notes of Table 3.

$* \mathrm{p}<0.10, * * \mathrm{p}<0.05, * * * \mathrm{p}<0.01$. 
Table A.8a - The effect of non-standard times on the GHQ index by education - Men

\begin{tabular}{|c|c|c|c|c|c|c|c|c|}
\hline & \multicolumn{2}{|c|}{$<$ O-level } & \multicolumn{2}{|c|}{ O-level } & \multicolumn{2}{|c|}{ A-level } & \multicolumn{2}{|c|}{$>$ A-level } \\
\hline & Coeff. & S.E. & Coeff. & S.E. & Coeff. & S.E. & Coeff. & S.E. \\
\hline \multicolumn{9}{|l|}{ OLS } \\
\hline Morning (MO) & -0.300 & $(0.660)$ & 0.911 & $(0.873)$ & -0.081 & $(1.175)$ & $-3.005 * *$ & $(1.216)$ \\
\hline Other parts of day (OD) & -0.442 & $(0.503)$ & -0.460 & $(0.450)$ & 1.022 & $(0.794)$ & $-1.121 *$ & $(0.691)$ \\
\hline Rotating shifts (RS) & -0.483 & $(0.374)$ & $-1.297 * * *$ & $(0.360)$ & -0.643 & $(0.608)$ & -0.610 & $(0.415)$ \\
\hline Varying patterns (VP) & -0.275 & $(0.447)$ & 0.248 & $(0.444)$ & 1.076 & $(0.739)$ & -0.403 & $(0.381)$ \\
\hline $\mathrm{N}$ & \multicolumn{2}{|c|}{2782} & \multicolumn{2}{|c|}{2796} & \multicolumn{2}{|c|}{1805} & \multicolumn{2}{|c|}{3783} \\
\hline $\mathrm{R}^{2}$ & \multicolumn{2}{|c|}{0.0887} & \multicolumn{2}{|c|}{0.0855} & \multicolumn{2}{|c|}{0.1108} & \multicolumn{2}{|c|}{0.0685} \\
\hline \multicolumn{9}{|l|}{$\mathrm{FE}$} \\
\hline Entry into MO & -1.193 & $(1.356)$ & $1.956 *$ & (1.104) & -0.271 & $(2.083)$ & 1.014 & $(2.237)$ \\
\hline Exit from MO & -1.480 & $(1.052)$ & $-2.287 * *$ & $(0.986)$ & 0.566 & $(2.439)$ & $5.062 * *$ & $(2.421)$ \\
\hline Stay in MO & 0.076 & $(0.643)$ & -0.344 & $(1.087)$ & -0.307 & (1.396) & -0.427 & (1.861) \\
\hline Entry into OD & -0.290 & $(0.748)$ & $-1.362 *$ & $(0.770)$ & -0.010 & $(1.345)$ & 0.494 & (1.231) \\
\hline Exit from OD & 0.542 & $(0.740)$ & -0.835 & $(0.625)$ & -0.811 & (1.051) & 0.966 & (1.201) \\
\hline Stay in OD & -0.133 & $(0.495)$ & 0.454 & $(0.606)$ & 0.067 & $(0.777)$ & 0.198 & (1.336) \\
\hline Entry into RS & $-1.766 * * *$ & $(0.612)$ & 0.619 & $(0.652)$ & -0.738 & $(0.758)$ & 0.227 & $(0.738)$ \\
\hline Exit from RS & -0.510 & $(0.555)$ & -0.099 & $(0.634)$ & 0.034 & $(0.856)$ & -0.568 & $(0.682)$ \\
\hline Stay in RS & -0.041 & $(0.252)$ & -0.422 & $(0.296)$ & 0.177 & $(0.405)$ & 0.050 & $(0.352)$ \\
\hline Entry into VP & -0.298 & $(0.554)$ & 0.106 & $(0.563)$ & -0.373 & $(0.892)$ & -0.747 & $(0.477)$ \\
\hline Exit from VP & $1.514 * * *$ & $(0.559)$ & $-1.340 * *$ & $(0.591)$ & -0.193 & $(0.922)$ & -0.225 & $(0.531)$ \\
\hline Stay in VP & -0.542 & $(0.468)$ & -0.328 & $(0.476)$ & 0.217 & $(0.769)$ & 0.140 & $(0.349)$ \\
\hline $\mathrm{N}$ & \multicolumn{2}{|c|}{2204} & \multicolumn{2}{|c|}{2165} & \multicolumn{2}{|c|}{1432} & \multicolumn{2}{|c|}{3108} \\
\hline $\mathrm{R}^{2}$ & \multicolumn{2}{|c|}{0.0425} & \multicolumn{2}{|c|}{0.0458} & \multicolumn{2}{|c|}{0.0690} & \multicolumn{2}{|c|}{0.0240} \\
\hline \multicolumn{9}{|l|}{$\mathrm{FE}(-2)$} \\
\hline Entry into MO & -2.333 & (2.019) & -2.954 & (1.832) & -4.815 & $(3.441)$ & -0.199 & $(2.867)$ \\
\hline Exit from MO & 0.399 & (1.409) & -0.249 & (1.477) & -0.530 & (2.539) & 1.327 & $(3.486)$ \\
\hline Stay in MO & 0.133 & $(0.829)$ & -2.176 & (1.747) & 1.184 & (1.892) & 3.355 & $(2.526)$ \\
\hline Entry into AF & -0.493 & (1.032) & -1.171 & (1.108) & 3.076 & (1.967) & -0.972 & (1.568) \\
\hline Exit from AF & 0.082 & (1.095) & 0.086 & $(0.917)$ & 0.453 & (1.469) & -1.551 & (1.896) \\
\hline Stay in AF & 0.110 & $(0.625)$ & 0.180 & $(0.833)$ & -0.412 & (0.947) & 0.422 & (1.683) \\
\hline Entry into $\mathrm{RS}$ & 0.307 & (0.910) & -0.753 & $(0.987)$ & -0.969 & (0.917) & 1.185 & $(0.978)$ \\
\hline Exit from RS & -0.888 & $(0.772)$ & 0.724 & $(0.959)$ & 0.197 & (1.416) & -0.029 & $(0.964)$ \\
\hline Stay in RS & -0.373 & $(0.322)$ & 0.379 & $(0.408)$ & 0.836 & $(0.519)$ & -0.115 & $(0.424)$ \\
\hline Entry into VP & -0.800 & (1.167) & -0.614 & (1.003) & 1.509 & (1.541) & 1.056 & $(0.803)$ \\
\hline Exit from VP & 0.272 & (0.918) & $1.605 *$ & $(0.866)$ & -0.460 & (1.337) & -0.440 & (0.693) \\
\hline Stay in VP & 0.368 & $(0.587)$ & -0.023 & $(0.664)$ & -0.118 & (0.974) & 0.238 & $(0.434)$ \\
\hline $\mathrm{N}$ & \multirow{2}{*}{\multicolumn{2}{|c|}{$\begin{array}{c}1365 \\
0.0375\end{array}$}} & \multirow{2}{*}{\multicolumn{2}{|c|}{$\begin{array}{c}1307 \\
0.0442\end{array}$}} & & & 198 & \\
\hline $\mathrm{R}^{2}$ & & & & & & & 0.02 & \\
\hline
\end{tabular}

Notes: The base category in the OLS regressions is 'during the day'. For definitions and variables included in the regressions, see notes of Table 3.

$* \mathrm{p}<0.10, * * \mathrm{p}<0.05, * * * \mathrm{p}<0.01$. 
Table A.8b - The effect of non-standard times on the GHQ index status by education - Women

\begin{tabular}{|c|c|c|c|c|c|c|c|c|}
\hline & \multicolumn{2}{|c|}{$<$ O-level } & \multicolumn{2}{|c|}{ O-level } & \multicolumn{2}{|c|}{ A-level } & \multicolumn{2}{|c|}{$>$ A-level } \\
\hline & Coeff. & S.E. & Coeff. & S.E. & Coeff. & S.E. & Coeff. & S.E. \\
\hline \multicolumn{9}{|l|}{ OLS } \\
\hline Morning (MO) & 0.226 & $(0.357)$ & 0.536 & $(0.437)$ & -1.274 & $(0.836)$ & -0.451 & $(0.494)$ \\
\hline Other parts of day (OD) & 0.201 & $(0.355)$ & -0.018 & $(0.373)$ & 0.652 & $(0.668)$ & 0.068 & $(0.586)$ \\
\hline Rotating shifts (RS) & 0.197 & $(0.469)$ & $-1.358 * * *$ & $(0.378)$ & -0.848 & $(0.666)$ & 0.593 & $(0.533)$ \\
\hline Varying patterns (VP) & -0.327 & $(0.452)$ & -0.294 & $(0.379)$ & 0.309 & $(0.616)$ & -0.541 & $(0.373)$ \\
\hline $\begin{array}{l}\mathrm{N} \\
\mathrm{R}^{2}\end{array}$ & \multicolumn{2}{|c|}{0.0723} & \multicolumn{2}{|c|}{0.0577} & \multicolumn{2}{|c|}{0.0854} & \multicolumn{2}{|c|}{0.0450} \\
\hline \multicolumn{9}{|l|}{ FE } \\
\hline Entry into MO & -0.319 & $(0.561)$ & -0.187 & $(0.729)$ & $-2.720 *$ & $(1.509)$ & -0.463 & $(1.065)$ \\
\hline Exit from MO & -0.798 & $(0.566)$ & $-1.839 * * *$ & $(0.680)$ & -2.282 & $(1.505)$ & -0.196 & $(0.937)$ \\
\hline Stay in MO & 0.016 & $(0.331)$ & -0.416 & $(0.436)$ & -0.099 & (1.029) & 0.012 & $(0.686)$ \\
\hline Entry into OD & -0.721 & $(0.660)$ & 0.735 & $(0.667)$ & -0.547 & (1.504) & $-3.320 * * *$ & (1.137) \\
\hline Exit from OD & -0.503 & $(0.557)$ & -0.554 & $(0.523)$ & 0.156 & (1.151) & $1.777 *$ & $(0.933)$ \\
\hline Stay in OD & 0.003 & $(0.329)$ & 0.365 & $(0.385)$ & -0.165 & $(0.858)$ & 0.480 & $(0.627)$ \\
\hline Entry into RS & $-1.301 *$ & $(0.778)$ & 0.381 & $(0.850)$ & -2.426 & (1.697) & 0.682 & $(0.878)$ \\
\hline Exit from RS & -0.748 & $(0.739)$ & 0.078 & $(0.789)$ & -0.713 & (1.529) & -0.035 & $(0.802)$ \\
\hline Stay in RS & $0.949 * *$ & $(0.438)$ & 0.352 & $(0.459)$ & -0.268 & $(0.864)$ & 0.187 & $(0.518)$ \\
\hline Entry into VP & -0.880 & $(0.597)$ & 0.022 & $(0.614)$ & -0.167 & (1.097) & -0.314 & $(0.623)$ \\
\hline Exit from VP & $1.205 * *$ & $(0.606)$ & -0.062 & $(0.561)$ & 1.011 & (1.284) & $1.538 * *$ & $(0.659)$ \\
\hline Stay in VP & 0.285 & $(0.445)$ & 0.270 & $(0.572)$ & -0.330 & (1.051) & 0.564 & $(0.465)$ \\
\hline $\mathrm{N}$ & \multicolumn{2}{|c|}{2994} & \multicolumn{2}{|c|}{3187} & \multicolumn{2}{|c|}{1061} & \multicolumn{2}{|c|}{2728} \\
\hline $\mathrm{R}^{2}$ & \multicolumn{2}{|c|}{0.0360} & \multicolumn{2}{|c|}{0.0261} & \multicolumn{2}{|c|}{0.0682} & \multicolumn{2}{|c|}{0.0258} \\
\hline \multicolumn{9}{|l|}{$\mathrm{FE}(-2)$} \\
\hline Entry into MO & $-1.555 *$ & $(0.840)$ & -1.330 & $(1.057)$ & -3.399 & $(2.282)$ & -0.052 & $(1.297)$ \\
\hline Exit from MO & $1.439 *$ & $(0.853)$ & 0.554 & $(0.976)$ & -2.734 & $(2.414)$ & 0.787 & $(1.243)$ \\
\hline Stay in MO & 0.055 & $(0.450)$ & -0.123 & $(0.557)$ & -0.269 & $(1.473)$ & -0.386 & $(0.837)$ \\
\hline Entry into AF & -0.915 & $(0.951)$ & -0.627 & $(0.882)$ & -0.504 & $(2.275)$ & 0.534 & $(1.407)$ \\
\hline Exit from AF & 0.411 & $(0.851)$ & -0.684 & $(0.712)$ & $3.812 *$ & $(1.682)$ & 0.782 & $(1.218)$ \\
\hline Stay in AF & 0.090 & $(0.433)$ & 0.002 & $(0.477)$ & -1.459 & $(1.148)$ & 0.592 & $(0.781)$ \\
\hline Entry into RS & $2.345 * *$ & (1.089) & -0.600 & $(1.212)$ & 0.545 & $(2.596)$ & -1.931 & $(1.246)$ \\
\hline Exit from RS & -1.610 & (1.257) & 0.577 & (1.216) & -0.295 & $(2.662)$ & 0.200 & $(1.115)$ \\
\hline Stay in RS & 0.402 & $(0.571)$ & 0.067 & $(0.568)$ & -0.751 & $(1.314)$ & 0.162 & $(0.632)$ \\
\hline Entry into VP & 1.367 & (1.089) & 0.110 & $(0.981)$ & 0.544 & $(2.055)$ & -1.920 & $(1.278)$ \\
\hline Exit from VP & 0.271 & $(0.908)$ & 0.795 & $(0.729)$ & 1.415 & $(2.175)$ & 0.746 & $(0.937)$ \\
\hline Stay in VP & -0.296 & $(0.565)$ & -0.713 & $(0.703)$ & 1.588 & (1.511) & 0.245 & $(0.588)$ \\
\hline $\mathrm{N}$ & \multicolumn{2}{|c|}{1895} & \multicolumn{2}{|c|}{1999} & \multicolumn{2}{|c|}{656} & 174 & \\
\hline $\mathrm{R}^{2}$ & 0.04 & & 0.03 & & 0.1 & & 0.02 & \\
\hline
\end{tabular}

Notes: The base category in the OLS regressions is 'during the day'. For definitions and variables included in the regressions, see notes of Table 3.

$* \mathrm{p}<0.10, * * \mathrm{p}<0.05, * * \mathrm{p}<0.01$. 
Table A.9a - The effect of non-standard hours on the GHQ index by education - Men

\begin{tabular}{|c|c|c|c|c|c|c|c|c|}
\hline & \multicolumn{2}{|c|}{$<$ O-level } & \multicolumn{2}{|c|}{ O-level } & \multicolumn{2}{|c|}{ A-level } & \multicolumn{2}{|c|}{$>$ A-level } \\
\hline & Coeff. & S.E. & Coeff. & S.E. & Coeff. & S.E. & Coeff. & S.E. \\
\hline \multicolumn{9}{|l|}{$\overline{\text { OLS }}$} \\
\hline Long hours (LH) & -0.404 & $(0.270)$ & $-0.478 *$ & $(0.264)$ & 0.380 & $(0.365)$ & -0.137 & $(0.246)$ \\
\hline Medium hours (MH) & -0.091 & $(0.732)$ & 0.435 & $(0.666)$ & 0.034 & $(0.946)$ & -0.221 & $(1.033)$ \\
\hline Short hours $(\mathrm{SH})$ & -0.844 & $(0.696)$ & 0.544 & $(0.568)$ & 1.319 & (1.101) & -0.078 & $(1.012)$ \\
\hline $\mathrm{N}$ & \multicolumn{2}{|c|}{2782} & \multicolumn{2}{|c|}{2796} & \multicolumn{2}{|c|}{1805} & \multicolumn{2}{|c|}{3783} \\
\hline $\mathrm{R}^{2}$ & \multicolumn{2}{|c|}{0.0890} & \multicolumn{2}{|c|}{0.0788} & \multicolumn{2}{|c|}{0.1070} & \multicolumn{2}{|c|}{0.0655} \\
\hline \multicolumn{9}{|l|}{ FE } \\
\hline Entry into LH & 0.038 & $(0.313)$ & -0.501 & $(0.364)$ & 0.232 & $(0.445)$ & -0.042 & $(0.319)$ \\
\hline Exit from $\mathrm{LH}$ & 0.139 & $(0.315)$ & 0.545 & $(0.387)$ & 0.172 & $(0.451)$ & -0.184 & $(0.330)$ \\
\hline Stay in LH & -0.112 & $(0.220)$ & -0.017 & $(0.265)$ & 0.020 & $(0.313)$ & $-0.417 *$ & $(0.217)$ \\
\hline Entry into MH & -1.036 & $(1.477)$ & -0.168 & $(0.992)$ & 1.362 & (1.643) & -0.505 & (1.453) \\
\hline Exit from $\mathrm{MH}$ & -0.209 & $(1.036)$ & -0.020 & $(0.827)$ & -1.081 & $(1.489)$ & -0.003 & $(1.326)$ \\
\hline Stay in $\mathrm{MH}$ & -0.152 & (1.300) & 1.344 & (1.127) & 0.992 & (2.013) & 0.221 & (1.319) \\
\hline Entry into SH & -2.220 & $(1.516)$ & 2.262 & $(1.752)$ & -0.489 & (1.811) & 1.441 & $(1.572)$ \\
\hline Exit from $\mathrm{SH}$ & -1.639 & (1.178) & -0.763 & $(0.741)$ & $-3.792 *$ & (1.626) & 0.979 & (1.236) \\
\hline Stay in SH & $3.273 * *$ & (1.288) & -0.054 & $(0.592)$ & $5.716 *$ & $(2.674)$ & 1.707 & $(1.400)$ \\
\hline $\mathrm{N}$ & \multicolumn{2}{|c|}{2204} & \multicolumn{2}{|c|}{2165} & \multicolumn{2}{|c|}{1432} & \multicolumn{2}{|c|}{3108} \\
\hline $\mathrm{R}^{2}$ & \multicolumn{2}{|c|}{0.0401} & \multicolumn{2}{|c|}{0.0399} & \multicolumn{2}{|c|}{0.0746} & \multicolumn{2}{|c|}{0.0232} \\
\hline \multicolumn{9}{|l|}{$\mathrm{FE}(-2)$} \\
\hline Entry into LH & -0.292 & $(0.414)$ & -0.202 & $(0.509)$ & -0.901 & $(0.617)$ & 0.077 & $(0.387)$ \\
\hline Exit from LH & 0.570 & $(0.417)$ & -0.188 & $(0.533)$ & 0.768 & $(0.596)$ & 0.039 & $(0.402)$ \\
\hline Stay in LH & 0.478 & $(0.295)$ & 0.285 & $(0.377)$ & -0.017 & $(0.404)$ & -0.187 & $(0.276)$ \\
\hline Entry into $\mathrm{MH}$ & -1.380 & (1.924) & -1.020 & (1.273) & -0.014 & (1.951) & -0.009 & (1.884) \\
\hline Exit from $\mathrm{MH}$ & -2.494 & (1.709) & 1.965 & (1.300) & -0.365 & $(2.205)$ & -0.053 & (1.779) \\
\hline Stay in $\mathrm{MH}$ & -2.649 & (1.712) & -1.067 & (1.834) & 2.300 & (3.320) & $2.717 *$ & (1.653) \\
\hline Entry into SH & 0.095 & (2.061) & -1.141 & (3.033) & 3.408 & $(5.072)$ & 1.037 & $(2.251)$ \\
\hline Exit from $\mathrm{SH}$ & 1.124 & (1.666) & -1.505 & $(0.963)$ & 1.509 & (1.957) & -0.244 & $(1.542)$ \\
\hline Stay in SH & 2.128 & (1.738) & 0.921 & $(0.718)$ & 4.105 & $(2.724)$ & 0.339 & $(1.837)$ \\
\hline $\mathrm{N}$ & \multicolumn{2}{|c|}{1365} & \multicolumn{2}{|c|}{1307} & \multicolumn{2}{|c|}{880} & \multicolumn{2}{|c|}{1985} \\
\hline $\mathrm{R}^{2}$ & \multicolumn{2}{|c|}{0.0417} & \multicolumn{2}{|c|}{0.0453} & 0.0 & & 0.0 & \\
\hline
\end{tabular}

Notes: The base category in the OLS regressions is 'normal hours' (30-48 per week). For definitions and variables included in the regressions, see notes of Table 3.

$* \mathrm{p}<0.10, * * \mathrm{p}<0.05, * * * \mathrm{p}<0.01$. 
Table A.9b - The effect of non-standard hours on the GHQ index by education - Women

\begin{tabular}{|c|c|c|c|c|c|c|c|c|}
\hline & \multicolumn{2}{|c|}{$<$ O-level } & \multicolumn{2}{|c|}{ O-level } & \multicolumn{2}{|c|}{ A-level } & \multicolumn{2}{|c|}{$>$ A-level } \\
\hline & Coeff. & S.E. & Coeff. & S.E. & Coeff. & S.E. & Coeff. & S.E. \\
\hline \multicolumn{9}{|l|}{$\overline{\text { OLS }}$} \\
\hline Long hours (LH) & 0.261 & $(0.649)$ & -0.642 & $(0.436)$ & 1.281 & $(0.805)$ & 0.294 & $(0.349)$ \\
\hline Medium hours (MH) & 0.185 & $(0.294)$ & 0.327 & $(0.302)$ & 0.824 & $(0.502)$ & -0.464 & $(0.372)$ \\
\hline Short hours (SH) & 0.180 & $(0.387)$ & 0.218 & $(0.342)$ & 0.993 & $(0.623)$ & -0.687 & $(0.473)$ \\
\hline $\mathrm{N}$ & \multicolumn{2}{|c|}{3867} & \multicolumn{2}{|c|}{4136} & \multicolumn{2}{|c|}{1415} & \multicolumn{2}{|c|}{3390} \\
\hline $\mathrm{R}^{2}$ & \multicolumn{2}{|c|}{0.0718} & \multicolumn{2}{|c|}{0.0543} & \multicolumn{2}{|c|}{0.0848} & \multicolumn{2}{|c|}{0.0449} \\
\hline \multicolumn{9}{|l|}{ FE } \\
\hline Entry into LH & 0.672 & $(0.663)$ & -0.162 & $(0.624)$ & $2.353 * *$ & $(1.142)$ & -0.552 & $(0.480)$ \\
\hline Exit from $\mathrm{LH}$ & 0.278 & $(0.694)$ & -0.145 & $(0.657)$ & 0.949 & $(1.325)$ & -0.074 & $(0.492)$ \\
\hline Stay in LH & -0.737 & $(0.741)$ & 0.880 & $(0.695)$ & -1.889 & $(1.268)$ & $0.698 *$ & $(0.376)$ \\
\hline Entry into MH & 0.692 & $(0.508)$ & -0.404 & $(0.534)$ & $1.769 *$ & (1.039) & -0.066 & $(0.667)$ \\
\hline Exit from $\mathrm{MH}$ & -0.443 & $(0.464)$ & 0.052 & $(0.451)$ & $-2.181 * *$ & $(0.953)$ & 0.780 & $(0.673)$ \\
\hline Stay in $\mathrm{MH}$ & -0.373 & $(0.392)$ & 0.056 & $(0.413)$ & 0.552 & $(0.831)$ & 0.258 & $(0.536)$ \\
\hline Entry into SH & 0.210 & $(0.698)$ & -0.104 & $(0.639)$ & $3.608 * * *$ & $(1.272)$ & 0.329 & $(0.963)$ \\
\hline Exit from $\mathrm{SH}$ & $-1.424 * *$ & $(0.575)$ & 0.436 & $(0.515)$ & -0.986 & (1.146) & 0.145 & $(0.787)$ \\
\hline Stay in SH & -0.099 & (0.409) & -0.031 & $(0.382)$ & 0.250 & $(0.900)$ & 0.315 & $(0.595)$ \\
\hline $\mathrm{N}$ & \multicolumn{2}{|c|}{2994} & \multicolumn{2}{|c|}{3187} & \multicolumn{2}{|c|}{1061} & \multicolumn{2}{|c|}{2728} \\
\hline $\mathrm{R}^{2}$ & \multicolumn{2}{|c|}{0.0318} & \multicolumn{2}{|c|}{0.0230} & \multicolumn{2}{|c|}{0.0790} & \multicolumn{2}{|c|}{0.0207} \\
\hline \multicolumn{9}{|l|}{$\mathrm{FE}(-2)$} \\
\hline Entry into LH & 0.458 & $(0.900)$ & 1.855 & $(0.788)$ & -0.002 & $(1.650)$ & -0.247 & $(0.601)$ \\
\hline Exit from LH & -0.746 & (1.080) & 0.235 & $(0.858)$ & $-3.334 *$ & (1.891) & -0.918 & $(0.663)$ \\
\hline Stay in LH & 0.964 & (1.046) & -0.970 & (1.047) & 3.168 & $(2.432)$ & 0.289 & $(0.493)$ \\
\hline Entry into $\mathrm{MH}$ & 0.744 & $(0.681)$ & -0.291 & $(0.682)$ & 2.154 & (1.428) & -1.176 & $(0.871)$ \\
\hline Exit from $\mathrm{MH}$ & -0.272 & $(0.669)$ & -0.372 & $(0.600)$ & -1.327 & (1.391) & 1.438 & $(0.891)$ \\
\hline Stay in $\mathrm{MH}$ & 0.434 & $(0.533)$ & -0.349 & $(0.521)$ & -0.335 & (1.162) & -0.182 & $(0.707)$ \\
\hline Entry into SH & 1.165 & (0.903) & -0.714 & $(0.831)$ & -0.157 & (1.861) & 0.478 & (1.197) \\
\hline Exit from $\mathrm{SH}$ & $-1.437 *$ & $(0.773)$ & 0.798 & $(0.700)$ & -0.586 & (1.637) & $3.275 * * *$ & (1.094) \\
\hline Stay in SH & 0.564 & $(0.550)$ & -0.370 & $(0.456)$ & 0.030 & $(1.271)$ & 0.272 & $(0.743)$ \\
\hline $\mathrm{N}$ & \multicolumn{2}{|c|}{1895} & \multicolumn{2}{|c|}{1999} & \multicolumn{2}{|c|}{656} & \multicolumn{2}{|c|}{1741} \\
\hline $\mathrm{R}^{2}$ & \multicolumn{2}{|c|}{0.0381} & \multicolumn{2}{|c|}{0.0373} & 0.09 & & 0.03 & \\
\hline
\end{tabular}

Notes: The base category in the OLS regressions is 'normal hours' (30-48 per week). For definitions and variables included in the regressions, see notes of Table 3.

$* \mathrm{p}<0.10, * * \mathrm{p}<0.05, * * \mathrm{p}<0.01$. 


\section{IZA Discussion Papers}

No Author(s)

141 R. Hujer M. Wellner

142 J. J. Dolado

F. Felgueroso

J. F. Jimeno

143 P. J. Luke

M. E. Schaffer

144 G. Saint-Paul

145 M.-S. Yun

146 T. K. Bauer

J. P. Haisken-DeNew

147 M. Belot

J. C. van Ours

148 L. Goerke

149 R. Lalive

J. C. van Ours

J. Zweimüller

150 J. DiNardo

K. F. Hallock

J.-St. Pischke

151 M. Ward

152 J. J. Dolado

F. Felgueroso

J. F. Jimeno

153 A. S. Kalwij

M. Gregory

154 M. Gerfin

M. Lechner

155 J. Hansen
Titel

Area

Date

The Effects of Public Sector Sponsored Training on Individual Employment Performance in East Germany

Explaining Youth Labor Market Problems in Spain: 3 Crowding-Out, Institutions, or Technology Shifts?

Wage Determination in Russia: An Econometric 4 Investigation

$4 / 00$

Flexibility vs. Rigidity: Does Spain have the worst of 1 both Worlds?

Decomposition Analysis for a Binary Choice Model 7

$4 / 00$

Employer Learning and the Returns to Schooling 5

$4 / 00$

$4 / 00$

Does the Recent Success of Some OECD 3

3

Countries in Lowering their Unemployment Rates

Lie in the Clever Design of their Labour Market

Reforms?

Employment Effects of Labour Taxation in an Efficiency Wage Model with Alternative Budget Constraints and Time Horizons

The Impact of Active Labor Market Programs and Benefit Entitlement Rules on the Duration of Unemployment

Unions and the Labor Market for Managers

Gender, Salary and Promotion in the Academic 5 Profession

$5 / 00$

The Role of the Minimum Wage in the Welfare 3 State: An Appraisal

$5 / 00$

Overtime Hours in Great Britain over the Period 3 1975-1999: A Panel Data Analysis

Microeconometric Evaluation of the Active Labour 6 Market Policy in Switzerland

$5 / 00$

$5 / 00$

The Duration of Immigrants' Unemployment Spells: $\quad 1 / 3$ Evidence from Sweden 


\begin{tabular}{|c|c|c|c|c|}
\hline 156 & $\begin{array}{l}\text { C. Dustmann } \\
\text { F. Fabbri }\end{array}$ & $\begin{array}{l}\text { Language Proficiency and Labour Market Per- } \\
\text { formance of Immigrants in the UK }\end{array}$ & 1 & $5 / 00$ \\
\hline 157 & $\begin{array}{l}\text { P. Apps } \\
\text { R. Rees }\end{array}$ & $\begin{array}{l}\text { Household Production, Full Consumption and } \\
\text { the Costs of Children }\end{array}$ & 7 & $5 / 00$ \\
\hline 158 & $\begin{array}{l}\text { A. Björklund } \\
\text { T. Eriksson } \\
\text { M. Jäntti } \\
\text { O. Raaum } \\
\text { E. Österbacka }\end{array}$ & $\begin{array}{l}\text { Brother Correlations in Earnings in Denmark, } \\
\text { Finland, Norway and Sweden Compared to the } \\
\text { United States }\end{array}$ & 5 & $5 / 00$ \\
\hline 159 & $\begin{array}{l}\text { P.- J. Jost } \\
\text { M. Kräkel }\end{array}$ & Preemptive Behavior in Sequential Tournaments & 5 & $5 / 00$ \\
\hline 160 & M. Lofstrom & $\begin{array}{l}\text { A Comparison of the Human Capital and Signaling } \\
\text { Models: The Case of the Self-Employed and the } \\
\text { Increase in the Schooling Premium in the 1980's }\end{array}$ & 5 & $6 / 00$ \\
\hline 161 & $\begin{array}{l}\text { V. Gimpelson } \\
\text { D. Treisman } \\
\text { G. Monusova }\end{array}$ & $\begin{array}{l}\text { Public Employment and Redistributive Politics: } \\
\text { Evidence from Russia's Regions }\end{array}$ & 4 & $6 / 00$ \\
\hline 162 & $\begin{array}{l}\text { C. Dustmann } \\
\text { M. E. Rochina- } \\
\text { Barrachina }\end{array}$ & $\begin{array}{l}\text { Selection Correction in Panel Data Models: An } \\
\text { Application to Labour Supply and Wages }\end{array}$ & 6 & $6 / 00$ \\
\hline 163 & $\begin{array}{l}\text { R. A. Hart } \\
\text { Y. Ma }\end{array}$ & Why do Firms Pay an Overtime Premium? & 5 & $6 / 00$ \\
\hline 164 & $\begin{array}{l}\text { M. A. Shields } \\
\text { S. Wheatley Price }\end{array}$ & $\begin{array}{l}\text { Racial Harassment, Job Satisfaction and Intentions } \\
\text { to Quit: Evidence from the British Nursing } \\
\text { Profession }\end{array}$ & 5 & $6 / 00$ \\
\hline 165 & P. J. Pedersen & $\begin{array}{l}\text { Immigration in a High Unemployment Economy: } \\
\text { The Recent Danish Experience }\end{array}$ & 1 & $6 / 00$ \\
\hline 166 & $\begin{array}{l}\text { Z. MacDonald } \\
\text { M. A. Shields }\end{array}$ & $\begin{array}{l}\text { The Impact of Alcohol Consumption on Occupa- } \\
\text { tional Attainment in England }\end{array}$ & 5 & $6 / 00$ \\
\hline 167 & $\begin{array}{l}\text { A. Barrett } \\
\text { J. FitzGerald } \\
\text { B. Nolan }\end{array}$ & $\begin{array}{l}\text { Earnings Inequality, Returns to Education and } \\
\text { Immigration into Ireland }\end{array}$ & 5 & $6 / 00$ \\
\hline 168 & $\begin{array}{l}\text { G. S. Epstein } \\
\text { A. L. Hillman }\end{array}$ & $\begin{array}{l}\text { Social Harmony at the Boundaries of the Welfare } \\
\text { State: Immigrants and Social Transfers }\end{array}$ & 3 & $6 / 00$ \\
\hline 169 & R. Winkelmann & $\begin{array}{l}\text { Immigration Policies and their Impact: The Case of } \\
\text { New Zealand and Australia }\end{array}$ & 1 & $7 / 00$ \\
\hline 170 & $\begin{array}{l}\text { T. K. Bauer } \\
\text { K. F. Zimmermann }\end{array}$ & $\begin{array}{l}\text { Immigration Policy in Integrated National } \\
\text { Economies }\end{array}$ & 1 & $7 / 00$ \\
\hline 171 & $\begin{array}{l}\text { C. Dustmann } \\
\text { F. Windmeijer }\end{array}$ & $\begin{array}{l}\text { Wages and the Demand for Health - A Life Cycle } \\
\text { Analysis }\end{array}$ & 5 & $7 / 00$ \\
\hline 172 & D. Card & $\begin{array}{l}\text { Reforming the Financial Incentives of the Welfare } \\
\text { System }\end{array}$ & 3 & $7 / 00$ \\
\hline 173 & D. S. Hamermesh & Timing, Togetherness and Time Windfalls & 5 & $7 / 00$ \\
\hline
\end{tabular}



M. Ward

180 T. K. Bauer I. N. Gang

E. Wasmer

Y. Zenou

184 M. Corak

B. Gustafsson

T. Österberg

185 H. Bonin

K. F. Zimmermann

A. S. Kalwij

A. Zaidi 
223 M. Rosholm former Soviet Union to Israel: Who is coming when?

228 G. Brunello

S. Comi

C. Lucifora

229 R. Coimbra

T. Lloyd-Braga

L. Modesto

230 L. Modesto
The College Wage Gap in 10 European and Earnings: An Empirical Study for Portugal 